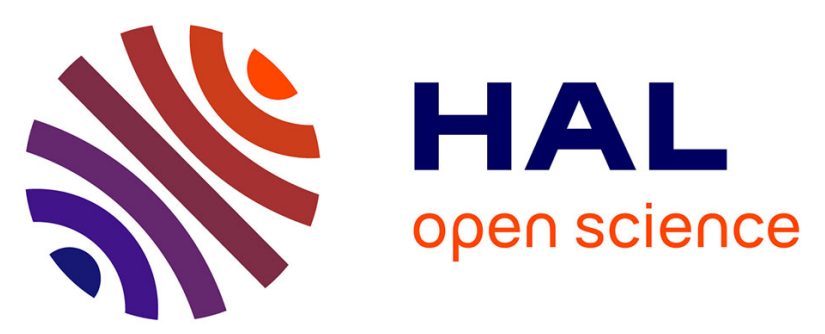

\title{
New insights on the distribution of interlayer water in bi-hydrated smectite from X-ray diffraction profile modeling 001 reflections
}

Eric Ferrage, Bruno Lanson, Natalie Malikova, Alain Plançon, Boris.A. Sakharov, Victor.A. Drits

\section{To cite this version:}

Eric Ferrage, Bruno Lanson, Natalie Malikova, Alain Plançon, Boris.A. Sakharov, et al.. New insights on the distribution of interlayer water in bi-hydrated smectite from X-ray diffraction profile modeling 001 reflections. Chemistry of Materials, 2005, 17 (13), pp.3499-3512. 10.1021/cm047995v . hal00193951

\section{HAL Id: hal-00193951 \\ https://hal.science/hal-00193951}

Submitted on 5 Dec 2007

HAL is a multi-disciplinary open access archive for the deposit and dissemination of scientific research documents, whether they are published or not. The documents may come from teaching and research institutions in France or abroad, or from public or private research centers.
L'archive ouverte pluridisciplinaire HAL, est destinée au dépôt et à la diffusion de documents scientifiques de niveau recherche, publiés ou non, émanant des établissements d'enseignement et de recherche français ou étrangers, des laboratoires publics ou privés. 
1 New insights on the distribution of interlayer water in bi-hydrated smectite from

7 Eric Ferrage ${ }^{1,2}$, Bruno Lanson ${ }^{1, *}$, Natalie Malikova ${ }^{2,3}$, Alain Plançon ${ }^{4}$, Boris A. Sakharov ${ }^{1,5}$, 8 and Victor A. Drits ${ }^{1,5}$

9

$10{ }^{1}$ Environmental Geochemistry Group, LGIT - Maison des Géosciences, Joseph Fourier 11 University - CNRS, BP53, F-38041 Grenoble cedex 9, France

$12{ }^{2}$ ANDRA, Parc de la Croix Blanche, 1-7 rue Jean Monnet, F-92298 Châtenay-Malabry 13 cedex, France

$14{ }^{3}$ Laboratory Liquides Ioniques \& Interfaces Chargées, Paris 06 University, Case 15 Courrier 51, 4 P1. Jussieu, F-75252 Paris; France

$16{ }^{4}$ Crystallography Laboratory, ISTO, University of Orléans - CNRS, F-45067 Orléans 17 Cedex 2, France.

$18{ }^{5}$ Geological Institute, Russian Academy of Sciences, 7 Pyzhevsky street, 109017

19 Moscow, Russia

20

$21 *$ Author to whom correspondence should be addressed.

22 e-mail : Bruno.Lanson@obs.ujf-grenoble.fr 
Abstract

The interlayer configuration proposed by Moore and Reynolds and commonly used to reproduce the $00 \ell$ reflections of bi-hydrated smectite is shown to be inconsistent with experimental X-ray diffraction data. ${ }^{1}$ The alternative configuration of interlayer species with cations located in the mid-plane of the interlayer and one sheet of $\mathrm{H}_{2} \mathrm{O}$ molecules on each side of this plane is also shown to imperfectly describe the actual structure of bi-hydrated smectites. Specifically, the thermal fluctuation of atomic positions (Debye-Waller factor) used to describe the positional disorder of interlayer $\mathrm{H}_{2} \mathrm{O}$ molecules has to be increased to unrealistic values to satisfactorily reproduce experimental X-ray diffraction data when using this model. A new configuration is thus proposed for the interlayer structure of bi-hydrated smectite. Cations are located in the mid-plane of the interlayer whereas $\mathrm{H}_{2} \mathrm{O}$ molecules are scattered about two main positions according to Gaussian-shaped distributions. This configuration allows reproducing all $00 \ell$ reflections with a high precision, with only one new variable parameter (width of the Gaussian function). The proposed configuration is consistent with those derived from Monte-Carlo calculations and allows matching more closely the amount of interlayer water that can be determined independently from water vapor adsorption/desorption isotherm experiments. In addition, the proposed configuration of interlayer species appears valid for both dioctahedral and trioctahedral smectites exhibiting octahedral and tetrahedral substitutions, respectively, thus not allowing to differentiate these expandable 2:1 phyllosilicates from their respective interlayer configuration. 


\section{Introduction}

45

Smectite is a 2:1 phyllosilicate whose layer structure consists of an octahedral sheet sandwiched in-between two siliceous tetrahedral sheets. Isomorphic substitutions in either tetrahedral or octahedral sites induce a permanent negative layer charge, which is compensated for by the presence of hydrated cations in the interlayer. The observation of $00 \ell$ basal reflections on X-ray diffraction (XRD) patterns has shown that with increasing relative humidity smectite expands stepwise, the different steps corresponding to the intercalation of $0,1,2$ or 3 sheets of $\mathrm{H}_{2} \mathrm{O}$ molecules in the interlayer. ${ }^{2-6}$ From these pioneer studies, it is now commonly accepted that the expandability of 2:1 phyllosilicates is controlled by factors such as the nature of interlayer cations, and the layer charge and its location (octahedral vs. tetrahedral). These general observations have led to different models in which crystalline swelling is controlled by the balance between the repulsive forces between neighboring $2: 1$ layers and the attractive forces between hydrated interlayer cations and the negatively-charged surface of siloxane sheets. ${ }^{6-11}$

The development of XRD modeling techniques allowed investigating structures in which different hydration states coexist thus improving these early observations. ${ }^{12-17}$ Ferrage et al. used such a modeling approach to characterize the hydration of several montmorillonite and beidellite samples and observed that the nature of the interlayer cation, and in particular its affinity for water, influences the layer thickness of bi-hydrated and monohydrated layers. ${ }^{18,19}$ They also confirmed that the relative proportions of the different layer types, which correspond to the different hydration states, depend on both the amount and the location of smectite layer charge. In addition, these authors showed that XRD peak profiles and position can be satisfactorily reproduced, especially over the low-angle region $\left(\sim 5-12^{\circ} 2 \theta\right.$ $\mathrm{Cu} \mathrm{K \alpha}$ ), only if hydration heterogeneity is taken into account. They were thus able to refine 
the structure of smectite and in particular to investigate atomic positions of interlayer species. In particular, they showed that the atomic positions reported by Moore and Reynolds for $\mathrm{H}_{2} \mathrm{O}$ molecules in bi-hydrated layers induce a dramatic misfit over the medium- to high-angle region $\left(12-50^{\circ} 2 \theta \mathrm{Cu} \mathrm{K} \alpha\right)$ by strongly modifying the intensity ratio between the different $00 \ell$ reflections. $^{1,18}$

The present article thus aims at refining further the structure of interlayer $\mathrm{H}_{2} \mathrm{O}$ in bihydrated smectites from the fit of experimental XRD patterns. The proposed structure is compared with the positional distribution commonly derived from Monte-Carlo simulations, whereas the adjusted amounts of interlayer water are compared with those determined experimentally from water vapor adsorption-desorption experiments.

9

(1)

\section{Background}

Smectite hydration heterogeneity as seen by XRD profile modeling. In agreement with the stepwise evolution of the $\mathrm{d}_{001}$ basal spacing on XRD patterns, the hydration state of smectite has been described using three layer types exhibiting different layer thickness corresponding to the common hydration states reported for montmorillonite in non-saturated conditions. Dehydrated layers (0W - Layer thickness 9.6-10.1 $)$ ), mono-hydrated layers (1W - Layer thickness $\sim 12.3-12.7 \AA)$, and bi-hydrated layers $(2 \mathrm{~W}$ - Layer thickness $\sim 15.1$ $15.8 \AA$ ) have thus been defined. In the first two layer types, interlayer cations are located in the mid-plane of the interlayer, together with $\mathrm{H}_{2} \mathrm{O}$ molecules for $1 \mathrm{~W}$ layers. For $2 \mathrm{~W}$ layers, interlayer cations are also commonly assumed to be located in the mid-plane of the interlayer. ${ }^{1}$ In addition, it is usually assumed that two planes of $\mathrm{H}_{2} \mathrm{O}$ molecules, each bearing $0.69 \mathrm{H}_{2} \mathrm{O}$ per $\mathrm{O}_{20}(\mathrm{OH})_{4}$, are located at 0.35 and $1.06 \AA$ from the cation along the $\mathrm{c}^{*}$ axis (Debye-Waller parameter $B_{\mathrm{wat}} \sim 2 \AA^{2}$ for these two planes), whereas a third denser plane (1.20 
$94 \mathrm{H}_{2} \mathrm{O}$ per $\left.\mathrm{O}_{20}(\mathrm{OH})_{4}\right)$ is located further from the central interlayer cation at $1.20 \AA$ along the $\mathrm{c}^{*}$ 95 axis $\left(B_{w a t}=11 \AA^{2}\right) .{ }^{1}$ The pattern calculated for the Ca-saturated reference SWy-1 montmorillonite (Ca-SWy-1) assuming a homogeneous $2 \mathrm{~W}$ hydration state and the above configuration for interlayer species is compared on Figure 1a to the experimental pattern recorded at $80 \% \mathrm{RH}$. With these usual hypotheses, the calculated pattern fits most of the experimental pattern features but significant discrepancies can be observed over the mediumto the high-angle region in spite of the low intensity diffracted. In particular, the position of the 005 reflection and the low-angle "tail" of the 002 reflection are not well reproduced (Figure 1a). Ferrage et al. challenged this usual configuration of interlayer species, and proposed an alternative configuration that includes a unique plane of $\mathrm{H}_{2} \mathrm{O}$ molecules located at $1.20 \AA$, along the $\mathrm{c}^{*}$ axis, on either side of the central interlayer cation (2WS configuration). ${ }^{18}$ The use of this $2 \mathrm{WS}$ configuration helps reducing the discrepancies observed for the 003-005 reflections. In particular, this configuration allows decreasing the relative intensity of the 003 and 004 reflections whereas the intensity of the 005 one is increased (Figure 1b). However, in the high-angle region the intensity ratio between the 007 and 008 reflections measured on the calculated pattern is inconsistent with that determined experimentally, although the intensity of the 008 reflection is correctly reproduced.

Ferrage et al. also demonstrated that the common hypothesis of a homogeneous hydration state for smectite is not consistent with the likely existence in smectite of structural heterogeneities affecting the layer charge distribution (from one interlayer to the other or within a given interlayer) and/or location (octahedral vs. tetrahedral). ${ }^{18}$ In turn these heterogeneities lead to the coexistence of different layer types in a single structure. Such hydration heterogeneity has been evidenced from the profile modeling of XRD patterns recorded on hydrated smectites. ${ }^{12-17}$ Ferrage et al. have shown that this heterogeneity is systematically observed whatever the interlayer cation, the relative humidity $(\mathrm{RH})$, and the 
119 amount and location of the layer charge deficit. ${ }^{18,19}$ It is thus essential to account for the

120 hydration heterogeneity to satisfactorily reproduce the experimental positions and profiles of 121 reflections.

Ferrage et al. have shown indeed that accounting for smectite hydration heterogeneity

123 allows fitting better the profiles of all experimental $00 \ell$ reflections. ${ }^{18,19}$ In particular

124 heterogeneous samples were modeled by combining the contributions of several structures,

125 each containing either one (periodic structure) or different layer types (mixed-layer structure -

126 MLS) randomly interstratified $(\mathrm{R}=0) .{ }^{18-20}$ These different contributions should be seen as a

127 simplified way to describe the actual hydration heterogeneity of the sample under

128 investigation, with the different layer types not being distributed at random in the different

129 crystallites. However, the coexistence of these contributions does not imply the actual

130 presence of populations of particles in the sample, as their relative proportions may vary as a

131 function of RH for example. ${ }^{18}$ To account for the heterogeneous distribution of the different

132 layer types within smectite crystallites, layers exhibiting the same hydration state that are

133 present in the different MLSs must have identical properties as they may be accounted for in

134 one or the other structure depending on the RH. In particular for a given XRD pattern, each

135 layer type must possess a constant crystal-chemistry in the different MLSs. It was possible to

136 reproduce the profile of all experimental $00 \ell$ reflections of the experimental XRD pattern

137 recorded on Ca-SWy-1 at $80 \%$ RH by considering two MLSs (Figure 1c) and the 2WS

138 configuration for interlayer water. ${ }^{18}$ Specifically, the position of the 005 reflection, the low-

139 angle shoulder of the 002 reflection and the "tails" of the 001 reflection are satisfactorily

140 reproduced by taking hydration heterogeneity into account. Accounting for hydration

141 heterogeneity also helps reproducing the relative intensity of higher-angle reflections (002,

142 003, 004, and 005 for example) but significant discrepancies that could result from an

143 incorrect structure model for interlayer water are still visible for high-angle reflections (Figure 
144 1c). Specifically, the 006, 007 and 008 reflections are not satisfactorily reproduced, as for

145 example the intensity ratio between the 007 and 008 reflections measured on experimental

146 and calculated patterns are inconsistent. These discrepancies are reduced by increasing the

147 Debye-Waller factor of $\mathrm{H}_{2} \mathrm{O}$ molecules $\left(\mathrm{B}_{\text {wat }}\right)$ from 2 to $11 \AA^{2}$ for this $2 \mathrm{WS}$ configuration of

148 interlayer $\mathrm{H}_{2} \mathrm{O}$ molecules (Figure 1d). ${ }^{18}$ However, such high values of the Debye-Waller

149 factor are not sufficient to conceal the disagreement for the intensity ratio between 007 and

150008 reflections, and thermal atomic fluctuations most likely do not adequately describe the

151 positional distribution of $\mathrm{H}_{2} \mathrm{O}$ molecules in $2 \mathrm{~W}$ smectite layers, and additional hypotheses

152 have to be sought.

153 Interlayer configuration of $\mathbf{2 W}$ smectite layers as seen by Monte-Carlo

154 simulations. In the above calculations, $\mathrm{H}_{2} \mathrm{O}$ molecules are distributed in discrete planes, and

155 the positional distribution of $\mathrm{H}_{2} \mathrm{O}$ molecules results only from their thermal motion. However,

156 this simplified description of the smectite interlayer structure does not allow fitting the

157 experimental XRD data (Figures 1c, 1d) most likely because the description of $\mathrm{H}_{2} \mathrm{O}$ molecule

158 positional disorder is incomplete. A more complete (realistic ?) description of the interlayer

159 structure may be obtained from Monte-Carlo (MC) simulations which allow taking into

160 account all interactions among interlayer species, as well as between these species and the 2:1

161 layer. $^{21}$ It is in particular possible to account for the hydration variability of interlayer cation

162 which can form either inner-sphere or outer-sphere complexes with the 2:1 layer surface,

163 leading to the existence or to the lack, respectively, of direct interactions with $\mathrm{O}$ atoms from

164 the layer surface. In the latter case, these interactions are screened by $\mathrm{H}_{2} \mathrm{O}$ molecules from the

165 cation hydration sphere. It has been shown that, as compared to other monovalent cations, $\mathrm{K}^{+}$

166 cations tend to form inner-sphere complexes in montmorillonite interlayers and that these

167 cations remain partially bound to the $2: 1$ clay surface even in the $2 \mathrm{~W}$ state. ${ }^{22,23}$ On the

168 contrary, $\mathrm{Li}^{+}$and $\mathrm{Na}^{+}$cations in $2 \mathrm{~W}$ smectites are located in the mid-plane of the interlayer. ${ }^{23-}$ 
The location of the layer charge deficit has also been shown to influence the hydration of interlayer $\mathrm{Na}^{+}$cations, the formation of inner-sphere complexes being favored by tetrahedral

171 substitutions. ${ }^{26}$ On the other hand, a majority of interlayer $\mathrm{Na}^{+}$cations is located in the mid-

172 plane of the interlayer for octahedrally substituted $2 \mathrm{~W}$ smectites. ${ }^{23,24}$ A similar influence of 173 the charge location was reported for $\mathrm{K}$ - and Li-saturated $2 \mathrm{~W}$ smectites. $^{22,25}$ In contrast, 174 whatever the charge location $\mathrm{Mg}^{2+}$ cations are systematically octahedrally coordinated in $2 \mathrm{~W}$ 175 smectites and located in the mid-plane of the interlayer. ${ }^{27,28}$ In any case, MC simulations most 176 often indicate that $\mathrm{H}_{2} \mathrm{O}$ molecules do not form a discrete plane but rather show that they are 177 distributed about a "most probable" position. In addition, the mixed charge location common 178 in smectite layers, and more especially in those of natural samples, can lead to the coexistence 179 in a single smectite interlayer of different complexes, thus broadening the water distribution 180 profile by perturbing the hydrogen bond network and the orientation of the water dipole. ${ }^{29}$

181 Even though MC simulations do not commonly account for smectite hydration heterogeneity, 182 which is best revealed by XRD analysis, such a description of $\mathrm{H}_{2} \mathrm{O}$ molecules positional 183 disorder could be the missing link toward a better structure determination of $\mathrm{H}_{2} \mathrm{O}$ 184 configuration in $2 \mathrm{~W}$ smectite layers.

\section{Materials and Methods}

Experimental. Samples investigated in the present work include two reference lowcharge montmorillonites (SWy-1 and SWy-2) available from the Source Clays Repository (http://www.agry.purdue.edu/cjohnston/sourceclays/index.html) and two synthetic saponite

191 samples. The latter samples were selected because of their contrasting layer charges $(0.8$ and

1921.4 per $\left.\mathrm{O}_{20}(\mathrm{OH})_{4}\right){ }^{30,31}$ The size fractionation of all samples, and their homoionic saturation 193 were performed as described by Ferrage et al. ${ }^{18}$ For all samples, oriented slides were prepared 
194 by drying at room temperature a clay slurry pipetted onto a glass slide. XRD patterns were 195 then recorded using a Bruker D5000 diffractometer equipped with a Kevex Si(Li) solid-state 196 detector, an Ansyco rh-plus 2250 humidity control device coupled to an Anton Paar TTK450 197 chamber. Usual scanning parameters were $0.04^{\circ} 2 \theta$ as step size and $6 \mathrm{~s}$ as counting time per 198 step over the $2-50^{\circ} 2 \theta \mathrm{Cu} \mathrm{K \alpha}$ angular range. The divergence slit, the two Soller slits, the 199 antiscatter and resolution slits were $0.5^{\circ}, 2.3^{\circ}, 2.3^{\circ}, 0.5^{\circ}$ and $0.06^{\circ}$, respectively. Data 200 collection conditions (60 and 80\% RH for Sr-saturated samples, 40 and $80 \% \mathrm{RH}$ for Ca201 saturated samples, and 80 or $90 \%$ RH for Na-saturated samples) were selected because of the 202 high amount of $2 \mathrm{~W}$ layers $(>90 \%)$ present in these conditions. ${ }^{18}$

Simulation of X-ray diffraction data. The algorithms developed initially by Drits 204 and coworkers were used to fit experimental XRD profiles over the $2-50^{\circ} 2 \theta \mathrm{CuK} \alpha$ range 205 using a trial-and-error approach. ${ }^{32-34}$ Instrumental and experimental factors such as horizontal 206 and vertical beam divergences, goniometer radius, length and thickness of the oriented slides 207 were measured and introduced without further adjustment. The mass absorption coefficient $208\left(\mu^{*}\right)$ was set to $45 \mathrm{~cm}^{2} \mathrm{~g}^{-1}$, as recommended by Moore and Reynolds, ${ }^{1}$ whereas the parameter 209 characterizing the preferred orientation of the particles in the sample $\left(\sigma^{*}\right)$ was considered as a 210 variable parameter. Additional variable parameters include the coherent scattering domain 211 size (CSDS) along the $\mathrm{c}^{*}$ axis which was characterized by a maximum CSDS value, set to 45 212 layers, and by a variable mean CSDS value $(\mathrm{N}) .{ }^{35}$ In addition, because of the weak bonds 213 between adjacent smectite layers, layer thickness was allowed to deviate from the average $\mathrm{d}_{001}$ 214 value. This cumulative deviation from periodicity, which is described as a "disorder of the 215 second type", ${ }^{36,37}$ is accounted for by introducing a variance parameter $\sigma_{\mathrm{z}}{ }^{18} \mathrm{z}$-coordinates of 216 all atoms building up the 2:1 layer framework as well as those present in the interlayer of $0 \mathrm{~W}$ 217 and $1 \mathrm{~W}$ layers were set as proposed by Moore and Reynolds. ${ }^{1}$ The interlayer structure of $2 \mathrm{~W}$ 218 layers has been refined to account for all features of experimental XRD patterns recorded on 
2W-dominated samples. In particular, a double Gaussian distribution of $\mathrm{H}_{2} \mathrm{O}$ molecules along 220 the $\mathrm{c}^{*}$ axis $(2 \mathrm{WG})$ was assumed. This $2 \mathrm{WG}$ model accounts both for the presence of a unique 221 plane of $\mathrm{H}_{2} \mathrm{O}$ molecules on either side of the mid-plane (Figures 1c, 1d) and for the positional 222 distribution of $\mathrm{H}_{2} \mathrm{O}$ molecules derived from $\mathrm{MC}$ simulations incomplete. The $2 \mathrm{WG}$ 223 distributions considered in the present study are symmetrical relative to the interlayer mid224 plane. They are characterized by the distance $(\Delta \mathrm{d})$ between this mid-plane, where interlayer cations are supposed to be located, and the position of the maximum density of the Gaussian distribution. In addition, the total amount of interlayer $\mathrm{H}_{2} \mathrm{O}$ molecules was refined together with the full width at half maximum intensity (FWHM) parameter of the Gaussian distribution. In the resulting structure model, $\mathrm{H}_{2} \mathrm{O}$ molecules were introduced using a $0.05 \AA$ step along the $\mathrm{c}^{*}$ axis, with a $\mathrm{B}_{\mathrm{wat}}$ factor equal to zero, as thermal motion is taken into account in MC calculations.

Two parameters were used to assess the overall goodness of fit. The unweighted $R_{p}$ 232 parameter was considered because this parameter is mainly influenced by the most intense 233 diffraction maxima such as the 001 reflection which contains essential information on the 234 proportions of the different layer types and on their respective layer thickness values. The $\mathrm{R}_{\mathrm{wp}}$ parameter was also used to better account for the overall fit quality, especially in the highangle regions. ${ }^{38}$ Accessory quartz reflections were omitted for the calculation of these 237 parameters. On their low-angle side, calculated XRD patterns are limited to $\sim 5^{\circ} 2 \theta \mathrm{CuK} \alpha$ 238 because significant discrepancies, possibly resulting from an incorrect description of 239 crystalline defects not challenging the results described in the present study, ${ }^{18}$ are observed 240 over the low-angle region. ${ }^{39}$

Monte-Carlo simulations. Monte-Carlo simulations in the NVT ensemble were used 242 to obtain a detailed spatial distribution of the different species within smectite interlayers. The 243 model montmorillonite-type smectite used in the simulations has a 
$244 \mathrm{Na}_{0.75}\left(\mathrm{Si}_{8}\right)\left(\mathrm{Al}_{3.25} \mathrm{Mg}_{0.75}\right) \mathrm{O}_{20}(\mathrm{OH})_{4}$ structural formula and exhibits substitutions only in the 245 octahedral sheet. The simulation box includes two 2:1 layers, each consisting of 8 unit cells 246 (total area: $20.72 \AA \times 17.94 \AA$, thickness of the $2: 1$ layer: $6.54 \AA$ ). The total negative charge 247 of the 2:1 layers was thus compensated for by $6 \mathrm{Na}^{+}$cations in the interlayer. The interlayer 248 shift between adjacent 2:1 layers was set to different arbitrary values for the two interlayers 249 considered and not allowed to vary during the calculation. For the typical layer thickness 250 value $(15.52 \AA)$ determined for Na-montmorillonite by XRD profile modeling, the water 251 content was estimated from the results of previous MC simulations performed with the NPT 252 ensemble. Series of such simulations allows the determination of layer thickness as a function 253 of water content, at constant pressure and temperature, ${ }^{40}$ and the water content was found to 254 be $9.5 \mathrm{H}_{2} \mathrm{O}$ molecules per $\mathrm{O}_{20}(\mathrm{OH})_{4}$. The resulting distributions of $\mathrm{H}_{2} \mathrm{O}$ molecules within $2 \mathrm{~W}$ 255 smectite interlayers were collected over 5 million MC steps, normalized and made symmetric 256 with respect to the mid-plane of the interlayer. The 2:1 layers were considered as rigid, and 257 modeled with the rigid SPC/E model (O-H bond $1.0 \AA$, angle $\mathrm{H}-\mathrm{O}-\mathrm{H} 109.47^{\circ}$, charges $258-0.848 \mathrm{e}^{-}$and $+0.424 \mathrm{e}^{-}$for oxygen and hydrogen atoms, respectively). Applied interaction 259 potentials were the Lennard-Jones 6-12 and Coulombic potentials. Each atom in the 260 simulation cell was thus characterized by two Van der Waals parameters and by its charge. 261 Additional details on the MC simulations can be found elsewhere. ${ }^{25,41-43}$ Density profiles 262 determined from MC calculations for interlayer sodium and $\mathrm{H}_{2} \mathrm{O}$ molecules were introduced 263 in the XRD profile calculation using a $0.075 \AA$ step.

\section{Results}

reflections. Figure 2 illustrates the influence of the different parameters used to describe the 
Gaussian distribution of $\mathrm{H}_{2} \mathrm{O}$ molecules, that is the total amount of $\mathrm{H}_{2} \mathrm{O}$ molecules $\left(\mathrm{nH}_{2} \mathrm{O}\right)$, $\Delta \mathrm{d}$, and FWHM, on the relative intensity of $00 \ell$ reflections. Calculations were performed assuming a periodic Ca-SWy-1 2W structure (layer thickness $=15.2 \AA$ ), and calculated 272 intensities were systematically normalized to that of the 001 reflection. By increasing the total 273 amount of $\mathrm{H}_{2} \mathrm{O}$ molecules the intensity of the $002,003,005$ reflections greatly increases, that 274 of the 008 reflection also increases but to a lower extent whereas 004,006 and 007 reflections are essentially unaffected (Figure 2). As its influence on 007 and 008 reflection intensity is 276 limited, the $\mathrm{nH}_{2} \mathrm{O}$ parameter will not affect significantly the intensity ratio between these two 277 reflections which is a common and critical discrepancy between experimental and calculated 278 profiles (Figures 1a-d). On the contrary, the 008:007 intensity ratio is strongly affected by the 279 FWHM of the Gaussian distribution, this ratio being minimum for a Dirac distribution and 280 increasing with the FWHM of the distribution. The 007 reflection is actually more intense 281 than the 008 one for FWHM values larger than $\sim 1.3 \AA$ (Figure 2). In addition this parameter 282 may be strongly constrained from its major influence on the intensity ratio between two 283 intense reflections ( 003 and 005 reflections) which can be reversed by increasing the width of 284 the Gaussian distribution of $\mathrm{H}_{2} \mathrm{O}$ molecules. However, the 003:005 ratio is also affected by 285 the $\Delta \mathrm{d}$ parameter which also affects the 008:007 intensity ratio, both ratios increasing with 286 increasing $\Delta \mathrm{d}$ values. By increasing either the $\Delta \mathrm{d}$ parameter or the FWHM, the intensity of 287 the 002 reflection is systematically decreased, whereas that of the 004 reflection is increased 288 or decreased, respectively. The intensity calculated for the 006 reflection is low whatever the 289 values used for these two parameters.

Modeling of XRD patterns. For all XRD patterns recorded on smectite samples, 291 calculations were performed using three different configurations of $\mathrm{H}_{2} \mathrm{O}$ molecules in the 292 interlayers of $2 \mathrm{~W}$ layers: (i) a $2 \mathrm{WS}$ configuration with two planes of $\mathrm{H}_{2} \mathrm{O}$ molecules 293 characterized by a $B_{\text {wat }}$ factor of $2 \AA^{2}$ and a $\Delta d$ parameter of $1.2 \AA^{18}$ (ii) a similar $2 \mathrm{WS}$ 
configuration with a larger Debye-Waller factor $\left(\mathrm{B}_{\text {wat }}=11 \AA^{2}\right)$, and (iii) a configuration with

$295 \mathrm{H}_{2} \mathrm{O}$ molecules distributed according to the $2 \mathrm{WG}$ configuration. Optimum parameters used to characterize smectite hydration heterogeneity, that is the relative proportions of the different MLSs coexisting in the sample and their compositions (relative proportions of $2 \mathrm{~W}, 1 \mathrm{~W}$, and 0W layers) are reported in Table 1 together with the layer thickness values for the different layer types, $\mathrm{N}, \sigma^{*}, \sigma_{\mathrm{z}}$ and the water content in $1 \mathrm{~W}$ layers. For $2 \mathrm{~W}$ layers, the water content, the $\Delta \mathrm{d}$ parameter, and the FWHM of the Gaussian distribution are reported in Table 2 for the different configurations of interlayer $\mathrm{H}_{2} \mathrm{O}$ molecules. performed for $2 \mathrm{WS}$ configurations of $\mathrm{H}_{2} \mathrm{O}$ molecules $(\Delta \mathrm{d}=1.2 \AA)$ and $\mathrm{B}_{\text {wat }}$ factors of 2 and $11 \AA^{2}$ have been described above (Figures 1c, 1d). The $2 \mathrm{WS}$ configuration provides a satisfactory fit to experimental patterns for $00 \ell$ reflections with $\ell<6$. However, this model does not allow concealing the discrepancy observed over the high-angle range, and more especially for the 008:007 intensity ratio, even if the Debye-Waller factor of $\mathrm{H}_{2} \mathrm{O}$ molecules is maximized $\left(\mathrm{B}_{\mathrm{wat}}=10-11 \AA^{2}\right){ }^{44}$ In this case, the water content and the $\Delta \mathrm{d}$ parameter are 309 increased from 6.6 to $6.8 \mathrm{H}_{2} \mathrm{O}$ per $\mathrm{O}_{20}(\mathrm{OH})_{4}$ and from 1.20 to $1.32 \AA$, respectively, as 310 compared to the $2 \mathrm{WS}$ configuration with $\mathrm{B}_{\mathrm{wat}}=2 \AA^{2}$ (Table 2). A 008:007 intensity ratio consistent with that observed experimentally can be obtained by considering the $2 \mathrm{WG}$ configuration for interlayer $\mathrm{H}_{2} \mathrm{O}$ molecules. In this case, broad Gaussian distributions were 313 assumed $(\mathrm{FWHM}=1.7 \AA)$, and both the water content and the $\Delta \mathrm{d}$ parameter were increased 314 as compared to alternative interlayer configurations (Table 2). This $2 \mathrm{WG}$ configuration also 315 allows fitting better the profile of the 005 reflection, but that of the 003 one is slightly altered 316 as a result of a low-angle tail broadening (Figure 1e). The combination of two structures, a main periodic one with only $2 \mathrm{~W}$ layers and a 318 second one containing the three layer types (Table 1), accounts for the hydration 
heterogeneity of sample Ca-SWy-2 at 40\% RH, and leads to the coexistence of $2 \mathrm{~W}, 1 \mathrm{~W}$, and 320 OW layers $\left(95 \%, 4 \%\right.$, and $1 \%$, respectively). ${ }^{20}$ The $2 \mathrm{WS}$ configuration allows describing most 321 features of the experimental XRD patterns $\left(R_{p}=1.31 \%\right.$ and $R_{w p}=8.13 \%-$ Figure $\left.3 a\right)$. 322 However, the 008 reflection is significantly more intense than the 007 one. By increasing the 323 Debye-Waller $B_{\text {wat }}$ factor from 2 to $11 \AA^{2}$, the 008:007 intensity ratio appears closer to the 324 experimental one although the two estimates of the fit quality are not affected (Figure 3b). 325 This ratio is best reproduced by assuming a $2 \mathrm{WG}$ distribution with a FWHM of $1.4 \AA$ (Figure 326 3c) although $R_{p}$ and $R_{w p}$ parameters are almost unaffected. As compared to the $2 \mathrm{WS}$ mode, the total amount of $\mathrm{H}_{2} \mathrm{O}$ molecules in such $2 \mathrm{WG}$ configuration is considerably increased from 6.2 (assuming a $\mathrm{B}_{\text {wat }}$ factor of $2 \AA^{2}$ ) to 7.8 per $\mathrm{O}_{20}(\mathrm{OH})_{4}$ (Table 2).

Sr-saturated montmorillonite. At both 60 and 80\% RH, the hydration heterogeneity of sample Sr-SWy-1 is minimum as it contains an overwhelming proportion of $2 \mathrm{~W}$ layers $(95$, and $96 \%$, respectively - Table 1$).{ }^{18}$ As for the Ca-saturated samples, the $2 \mathrm{WS}$ configuration for $\mathrm{H}_{2} \mathrm{O}$ molecules leads to a satisfactory fit to the experimental XRD patterns, especially for $00 \ell$ reflections with $\ell<6$, and for the 008 reflection (Figures $4 a, 5 a)$. However, significant 334 discrepancies between experimental and calculated patterns are visible for the 002 reflection 335 and the 008:007 intensity ratio. These discrepancies are significantly reduced by increasing the Debye-Waller factor of $\mathrm{H}_{2} \mathrm{O}$ molecules from 2 to $11 \AA^{2}$, but they do not vanish completely

337 (Figures 4b, 5b). The optimum fit to the experimental XRD patterns was again obtained 338 assuming a 2 WG distribution of interlayer $\mathrm{H}_{2} \mathrm{O}$ molecules with a large FWHM value (1.2, and $3391.5 \AA$ for Sr-SWy-1 samples recorded at 60 and $80 \% \mathrm{RH}$, respectively - Table 2; Figures 4c, 340 5c). For the two samples, both Rp and Rwp are lower for the $2 \mathrm{WG}$ configuration of interlayer $341 \mathrm{H}_{2} \mathrm{O}$ molecules than for the 2WS ones. Na-saturated montmorillonite. At $80 \% \mathrm{RH}$, the Na-SWy-2 sample exhibits a high 343 proportion $(92 \%)$ of $2 \mathrm{~W}$ layers whereas minor amounts of $1 \mathrm{~W}$ and $0 \mathrm{~W}$ layers $(5 \%$, and $3 \%$, 
respectively) account for the hydration heterogeneity (Table 1). As for the previous sample,

345 the 2WS configuration of $\mathrm{H}_{2} \mathrm{O}$ molecules leads to a satisfactory agreement between 346 experimental and calculated data, especially for $00 \ell$ reflections with $\ell<6$, and for the 008 347 reflection (Figure 6a). However, by using a Debye-Waller factor of $2 \AA^{2}$ the intensity 348 calculated for the 006 and 007 reflections are too low as compared to the experimental one. 349 Increasing the $\mathrm{B}_{\text {wat }}$ factor up to $11 \AA^{2}$ significantly reduces these discrepancies although the 350 008:007 intensity ratio remains imperfectly reproduced (Figure $6 \mathrm{~b}$ ). The optimum fit to the 351 experimental data for this sample was again obtained assuming a 2 WG distribution of $\mathrm{H}_{2} \mathrm{O}$ 352 molecules (Figure $6 \mathrm{c}-\mathrm{R}_{\mathrm{wp}}=5.33 \%, \mathrm{R}_{\mathrm{p}}=2.59 \%$ ). The $\Delta \mathrm{d}$ and FWHM parameters of this 3532 WG distribution are $1.50 \AA$ and $1.4 \AA$, respectively (Table 2). A similar fit to the 354 experimental data (Figure $6 \mathrm{~d}-\mathrm{R}_{\mathrm{wp}}=5.34 \%, \mathrm{R}_{\mathrm{p}}=2.57 \%$ ) was obtained assuming the 355 distribution of interlayer species shown on Figure 7, while all other parameters were kept 356 constant (Table 1). This distribution was derived from the MC simulations performed using 357 the NVT ensemble. MC calculated distributions exhibit a single peak for the oxygen atoms, 358 and two for the hydrogen atoms, between the interlayer mid-plane and the surface of the 2:1 359 layer, and are characteristic of the presence of a single plane of $\mathrm{H}_{2} \mathrm{O}$ molecules on either side 360 of the cation plane which is located in the center of the interlayer. The distance between the 361 maximum of the oxygen distribution and the maximum of the hydrogen distribution closer to 362 the 2:1 layer is $\sim 1.0 \AA$ which is the length of the $\mathrm{O}-\mathrm{H}$ bond in the water molecule. This 363 indicates a preferential orientation of the $\mathrm{H}_{2} \mathrm{O}$ molecules in the interlayer, with one of the O-H 364 bonds almost perpendicular to the surface of the 2:1 layer. Similar configurations of $\mathrm{H}_{2} \mathrm{O}$ 365 molecules in the interlayer of octahedrally-substituted smectites have been previously 366 reported from IR spectroscopy results, ${ }^{45}$ and from microscopic simulations. ${ }^{24}$ As for all other 367 samples, the amount of interlayer $\mathrm{H}_{2} \mathrm{O}$ molecules has to be increased, together with the $\Delta \mathrm{d}$ 368 parameter, as the positional distribution of these species increases (Table 2). 

synthetic saponites is minimum as they exhibit an overwhelming proportion of $2 \mathrm{~W}$ layers $(94$, and $97 \%$ for $\mathrm{Na}^{-S a p} \mathrm{p}_{0.8}$ and Na-Sap 1.4 samples, respectively - Table 1). As compared to the natural ones, these two synthetic samples present larger CSDS along the $\mathrm{c}^{*}$ axis, as evidenced by the sharpening of the $00 \ell$ reflections (Table $1-$ Figures 8,9 ). Layer thickness of $2 \mathrm{~W}$ layers decreases from $15.4 \AA$ to $15.0 \AA$ as the layer charge increases from 0.8 to 1.4 per $\mathrm{O}_{20}(\mathrm{OH})_{4}$ (samples Na-Sap 0.8 and Na-Sap 1.4 , respectively - Table 1). For both samples, the $2 \mathrm{WS}$ configuration of $\mathrm{H}_{2} \mathrm{O}$ molecules with $\mathrm{B}_{\mathrm{wat}}=2 \AA^{2}$ allows fitting satisfactorily $00 \ell$ reflections with $\ell<6$ (Figures 8a, 9a). Increasing the Debye-Waller factor up to $11 \AA^{2}$ leads to a perfect fit to the experimental data for the high-charge sample (Na-Sap 1.4 $_{1}$ - Figure $\left.9 \mathrm{~b}\right)$, whereas significant discrepancies are still observed between experimental and calculated patterns for 380 the low-charge sample $\left(\mathrm{Na}-\mathrm{Sap}_{0.8}\right.$ - Figure $\left.8 \mathrm{~b}\right)$. For this latter sample, the optimum fit to the experimental data was again obtained assuming a $2 \mathrm{WG}$ distribution of $\mathrm{H}_{2} \mathrm{O}$ molecules in the those obtained for natural samples (Figure 8c - Table 2). For the Na-Sap 1.4 sample, a fit similar to the one obtained with a $2 \mathrm{WS}$ distribution of $\mathrm{H}_{2} \mathrm{O}$ molecules and a high $\mathrm{B}_{\text {wat }}$ factor was obtained assuming a 2WG distribution of $\mathrm{H}_{2} \mathrm{O}$ molecules (Figures 9b, 9c). However, the FWHM parameter of this distribution is significantly lower $(0.8 \AA)$ than those typically obtained for natural samples (1.2-1.7 $\AA$ - Table 2).

\section{Discussion}

smectite interlayers. By accounting for smectite hydration heterogeneity, it is possible to model experimental XRD patterns thus gaining additional insights into the structure of 
smectite interlayers. It should be noted first that the initial assumption of identical properties

395 for all layers exhibiting the same hydration state and present in the different MLSs was

396 verified for all samples, thus validating the proposed description of smectite hydration

397 heterogeneity. In addition, the configuration of $\mathrm{H}_{2} \mathrm{O}$ molecules within $2 \mathrm{~W}$ smectite layers

398 commonly used for XRD pattern simulations can be discarded as it systematically leads to

399 major discrepancies between experimental and calculated profiles (Figure 10). ${ }^{18-20}$

400 Specifically, the use of this usual configuration systematically leads to poor fits to the 401 experimental XRD patterns for low-angle high-intensity reflections such as 003,004 , and 005 reflections (Figure 10). By contrast, the distribution of $\mathrm{H}_{2} \mathrm{O}$ molecules within a single plane on either side of the mid-plane interlayer (2WS configuration) allows both fitting the profiles

404 and reproducing the relative intensities of the $00 \ell$ reflections with $\ell<6$ (Figures $1 \mathrm{c}, 3 \mathrm{a}, 4 \mathrm{a}, 5 \mathrm{a}$, $4056 a, 8 a, 9 a){ }^{18}$ When assuming a Debye-Waller $B_{\text {wat }}$ factor of $2 \AA^{2}$, this model leads to significant discrepancies for high-order $00 \ell$ reflections, which are partly resolved by increasing the positional disorder of $\mathrm{H}_{2} \mathrm{O}$ molecules $\left(\mathrm{B}_{\mathrm{wat}}=11 \AA^{2}-\right.$ Figures $1 \mathrm{~d}, 3 \mathrm{~b}, 4 \mathrm{~b}, 5 \mathrm{~b}$, $6 b, 8 b, 9 b)$. However, except for sample Na-Sap ${ }_{1.4}$, such an increased $\mathrm{B}_{\text {wat }}$ factor does not allow fitting satisfactorily the high-order $00 \ell$ reflections, which would require unrealistically high $\mathrm{B}_{\text {wat }}$ factor values. In addition, the contrasting $\mathrm{B}_{\mathrm{wat}}$ factors adjusted for the two synthetic saponite samples recorded under similar $\mathrm{RH}$ conditions plead for a different origin to the actual positional disorder of $\mathrm{H}_{2} \mathrm{O}$ molecules in smectite interlayers.

414 model can be considered as an improved version of the 2WS model in which the actual 415 positional disorder of $\mathrm{H}_{2} \mathrm{O}$ molecules is better accounted for (Figures 1e, 3c, 4c, 5c, 6c, 8c, $4169 \mathrm{c})$. In the $2 \mathrm{WG}$ model the interlayer cation is considered to lie in a fixed position located in 417 the interlayer mid-plane and to have a Debye-Waller factor of $2 \AA^{2}$. This hypothesis does not 418 imply that the interlayer cations are not distributed as $\mathrm{H}_{2} \mathrm{O}$ molecules are, but it was assumed 
as a first approximation that thermal motion would be sufficient to account for their positional disorder In addition, the sensitivity to the positional disorder of these cations is much reduced as compared to $\mathrm{H}_{2} \mathrm{O}$ molecules as the former species accounts for a minor part of the overall electronic density in smectite interlayers. For example, at $80 \% \mathrm{RH} \mathrm{Ca}^{2+}$ cations account for only $6 \%$ of the interlayer electrons (Table 3 ).

When comparing the electronic density due to interlayer $\mathrm{H}_{2} \mathrm{O}$ molecules deduced from MC calculations with that obtained from XRD profile fitting (Figure 11a), it is possible to note that the overall profiles are globally alike in spite of significant differences. In particular the two planes of $\mathrm{H}_{2} \mathrm{O}$ molecules on either side of the interlayer mid-plane are much narrower in the MC calculations (FWHM $\sim 0.7 \AA$ as compared to $\sim 1.4 \AA$ for XRD profile fitting) which indicate also a significantly higher electron density in the interlayer mid-plane. The narrower distribution obtained from the $\mathrm{MC}$ simulation can be due in part to the fixed interlayer displacement between adjacent layers considered for the calculations although the influence of interlayer shift and/or layer rotation on the distribution of interlayer species derived from MC simulations is expected to be limited. The simple (simplistic ?) Gaussian functions used 434 to model the distribution of $\mathrm{H}_{2} \mathrm{O}$ molecules are both shifted toward the interlayer mid-plane 435 (by about $0.2 \AA$ ) and broadened as compared to MC calculations. Both the broadening and the shift of the Gaussian distributions are likely related to the specific profile of the MC distribution, and more especially to the high electron density in the interlayer mid-plane 438 (Figure 7). However, the XRD profiles calculated assuming the two models are almost 439 identical (Figures 6c, 6d), pleading for a limited sensitivity of calculated XRD patterns to 440 these two parameters if the actual distribution profile is unknown. Validity of the 2WG configuration model. Similar XRD patterns may be calculated 442 with 2 WG and 2 WS models by increasing the $B_{\text {wat }}$ factor in the latter model (Figures 8c, 8d, 443 and $9 \mathrm{~b}, 9 \mathrm{c})$. Because of the demonstrated sensitivity of calculated XRD patterns to the 
444 distribution of $\mathrm{H}_{2} \mathrm{O}$ molecules, this similarity can only result from similar contributions of $445 \mathrm{H}_{2} \mathrm{O}$ molecules to the structure factor in both models. Factors affecting the structure factor 446 include the scattering power, the position and the amount of considered species. If the origin 447 of the layer unit is set in the center of the layer octahedron, the contribution of $\mathrm{H}_{2} \mathrm{O}$ molecules 448 to the structure factor of $00 \ell$ reflections for a periodic $2 \mathrm{~W}$ smectite ( $2 \mathrm{WS}$ model) can be 449 expressed as:

$$
F_{\mathrm{H}_{2} \mathrm{O}}(00 \ell)=2 n_{\mathrm{H}_{2} \mathrm{O}} f_{B}\left(\frac{\sin \theta}{\lambda}\right)_{00 \ell} \cos (2 \pi \ell \mathrm{Z})
$$

where $f_{B}\left(\frac{\sin \theta}{\lambda}\right)_{00 \ell}$ is the scattering power of $\mathrm{H}_{2} \mathrm{O}$ molecules taking into account 452 their thermal motion $\left(\mathrm{B}_{\text {wat }}\right), n_{\mathrm{H}_{2} \mathrm{O}}$ is the amount of $\mathrm{H}_{2} \mathrm{O}$ molecules at $\mathrm{Z}=\frac{1}{2}-\frac{\Delta d}{h}$, h being 453 the layer thickness. $\Delta \mathrm{d}$ is the distance between the interlayer mid-plane and the positions of 454 the $\mathrm{H}_{2} \mathrm{O}$ molecules along the $\mathrm{c}^{*}$ axis. With increasing values of $\ell$, the contribution of $\mathrm{H}_{2} \mathrm{O}$ 455 molecules decreases together with $f_{B}(00 \ell)$ as a result of the thermal motion of $\mathrm{H}_{2} \mathrm{O}$ 456 molecules.

For the 2WG model, the contribution of interlayer $\mathrm{H}_{2} \mathrm{O}$ molecules to the structure 458 factor of $00 \ell$ reflections for a periodic $2 \mathrm{~W}$ smectite can be expressed as:

$$
F_{H_{2} \mathrm{O}}(00 \ell)=4 f\left(\frac{\sin \theta}{\lambda}\right)_{00 \ell} \cos \left(2 \pi \ell\left(\frac{1}{2}-\frac{\Delta d}{h}\right)\right) \sum_{m} n_{m} \cos \left(2 \pi \ell m \frac{\Delta z}{h}\right)
$$
where $f\left(\frac{\sin \theta}{\lambda}\right)_{00 \ell}$ is the scattering power of $\mathrm{H}_{2} \mathrm{O}$ molecules $\left(\mathrm{B}_{\text {wat }}=0\right)$, and $\Delta \mathrm{d}$ is the 461 distance along the $\mathrm{c}^{*}$ axis between the interlayer mid-plane and the position of the maximum 462 density of the Gaussian distribution. $n_{m}$ is the amount of $\mathrm{H}_{2} \mathrm{O}$ molecules at a given distance 463 ( $\mathrm{m} \Delta \mathrm{z}, \mathrm{m}$ being integer) from the maximum density of the Gaussian distribution. The sum $464 \sum_{m} n_{m}$ equals the total number of interlayer $\mathrm{H}_{2} \mathrm{O}$ molecules. For a given $\ell$ value, the 
positional distribution of $\mathrm{H}_{2} \mathrm{O}$ molecules disturbs their coherent scattering and thus decreases

466 their absolute contribution to the structure factor. The decrease becomes more important as 467 the $\ell$ indice increases. To quantify this decrease, Equation (2) can be expressed as:

$$
F_{\mathrm{H}_{2} \mathrm{O}}(00 \ell)=2 n_{\mathrm{H}_{2} \mathrm{O}}^{e f f} f\left(\frac{\sin \theta}{\lambda}\right)_{00 \ell} \cos \left(2 \pi \ell\left(\frac{1}{2}-\frac{\Delta d}{h}\right)\right) \sum_{m} n_{m} \cos \left(2 \pi \ell m \frac{\Delta Z}{h}\right)
$$

$$
\text { where } n_{\mathrm{H}_{2} \mathrm{O}}^{\text {eff }}=2 \sum_{m} n_{m} \cos \left(2 \pi \ell m \frac{\Delta Z}{h}\right) \text { is the effective amount of interlayer } \mathrm{H}_{2} \mathrm{O}
$$

molecules contributing to the structure factor. Equations (1) and (3) look similar but in the

sum determining the $n_{\mathrm{H}_{2} \mathrm{O}}^{\text {eff }}$ value, the cosine term is lower than 1 , and $n_{\mathrm{H}_{2} \mathrm{O}}^{\text {eff }}$ is thus lower

472 than the total number of $\mathrm{H}_{2} \mathrm{O}$ molecules. In addition, the $n_{\mathrm{H}_{2} \mathrm{O}}^{\text {eff }}$ value decreases with 473 increasing $\ell$ indices.

Thus both $2 \mathrm{WS}$ and $2 \mathrm{WG}$ models are essentially different although in both cases the contribution of interlayer $\mathrm{H}_{2} \mathrm{O}$ molecules to the structure factor is strongly decreasing with increasing $\ell$ indices. In the first case, the thermal motion of these interlayer species is entirely

477 responsible for the decrease whereas in the latter model the decrease is related to the 478 decreasing effective number of $\mathrm{H}_{2} \mathrm{O}$ molecules contributing to coherent diffraction effects. 479 Note that both models may produce similar diffraction effects if appropriate values are used 480 for the parameters describing the positional disorder of interlayer molecules. However, 481 unrealistically large values were obtained for the $\mathrm{B}_{\text {wat }}$ parameter when fitting Na-Sap 0.8 $482\left(\mathrm{~B}_{\mathrm{wat}}=30 \AA^{2}\right)$ as compared to Na-Sap ${ }_{1.4}\left(\mathrm{~B}_{\mathrm{wat}}=11 \AA^{2}\right)$ although both XRD patterns were 483 recorded under similar experimental conditions, and the $2 \mathrm{WG}$ configuration of $\mathrm{H}_{2} \mathrm{O}$ 484 molecules appears as more realistic than the 2WS one. Additional support for the 2WG model 485 arises from the close match between the number of interlayer $\mathrm{H}_{2} \mathrm{O}$ molecules determined 486 using the $2 \mathrm{WG}$ model and that measured independently from water vapor isotherms. 
$488 \mathrm{H}_{2} \mathrm{O}$ molecules can be approximated by weighing the water content hypothesized for each 489 layer type by the relative abundance of this layer type and compared to that obtained from 490 water vapor adsorption-desorption isotherm experiments (Table 3). ${ }^{18}$ The water content 491 determined by Ferrage et al. from XRD profile modeling assuming a 2WS model for the 492 distribution of interlayer $\mathrm{H}_{2} \mathrm{O}$ molecules was reasonably consistent with that obtained from 493 water vapor adsorption-desorption isotherm experiments. ${ }^{14,16,18}$ However, the 2WG configuration provides the best agreement with the water contents determined experimentally from water vapor adsorption-desorption isotherm experiments, the XRD values lying most often between the values obtained on either branches of the isotherm (Tables 2, 3). FWHM of $\mathrm{H}_{2} \mathrm{O}$ molecule Gaussian distribution. When using the $2 \mathrm{WG}$ model to 498 describe the distribution of $\mathrm{H}_{2} \mathrm{O}$ molecules in 2W layers, the FWHM parameter represents the 499 positional disorder of the species, which is characterized by the $\mathrm{B}_{\text {wat }}$ factor in usual models. 500 One may note that the diffraction effects resulting from the two configurations are similar and 501 lead to a significant decrease of the coherent scattering of $\mathrm{H}_{2} \mathrm{O}$ molecules with increasing 502 diffraction angle (see above). However, the $\mathrm{B}_{\text {wat }}$ factor should be about constant for a given 503 species whereas the FWHM parameter can be structurally interpreted. For example, when 504 increasing the RH, the FWHM of the Gaussian distribution systematically increases for Ca505 and Sr-saturated montmorillonites (Table 2 - Figures 11b, 11c) most likely to accommodate 506 the steady addition of $\mathrm{H}_{2} \mathrm{O}$ molecules weakly bound to the interlayer cation. On the contrary, 507 with increasing layer charge, Na-saturated saponite samples hold more $\mathrm{H}_{2} \mathrm{O}$ molecules for a 508 given RH value in a narrower distribution (Figure 11d-Table 2). A possible origin for such 509 narrowing of $\mathrm{H}_{2} \mathrm{O}$ molecule distributions is the increased polarization of these interlayer 510 species resulting from a stronger undersaturation of surface oxygen atoms. 
512 the interlayer cations, which are located in the interlayer mid-plane, and the maximum density 513 of the interlayer $\mathrm{H}_{2} \mathrm{O}$ molecule distribution function was also varied from one model to the 514 other, the maximum $\Delta \mathrm{d}$ values being obtained with the $2 \mathrm{WG}$ configuration of $\mathrm{H}_{2} \mathrm{O}$ molecules (Table 2). The $\Delta \mathrm{d}$ values reported in the present study represent only indicative values that could be used for XRD profile modeling but a more complete study should be carried out to determine the key factors that influence this parameter. and smectite are differentiated from their contrasting layer charge, vermiculite exhibiting a higher layer charge (1.2-1.8 per $\left.\mathrm{O}_{20}(\mathrm{OH})_{4}\right)$ than smectite $\left(0.4-1.2\right.$ per $\left.\mathrm{O}_{20}(\mathrm{OH})_{4}\right){ }^{46}$ This difference is usually revealed by the contrasting swelling behavior of the two minerals after magnesium saturation and glycerol solvation, vermiculite and smectite exhibiting basal spacings of $\sim 14 \AA$ and $\sim 18 \AA$, respectively, after such treatment. ${ }^{1,47,48}$ However, distinct hydration behavior has not been reported for these two mineral species, and the predominance of bi-hydrated layers has been documented for the two species as a function of relative 527 humidity. As a consequence, these two expandable 2:1 phyllosilicates will be considered together in the following.

For modeling XRD results of clay minerals containing $2 \mathrm{~W}$ layers, the interlayer water configuration usually assumed for bi-hydrated smectite is that used for the calculations

531 showed on Figures 1a and 10 and already described (Type I - Figure 12). ${ }^{1}$ This model does 532 not allow the description of experimental XRD patterns (Figure 10) and may be rejected. Most of the three-dimensional structural determinations of $2 \mathrm{~W}$ interlayer configuration were actually performed on vermiculite as this mineral frequently exhibits 
more accurate refinement of cation positions as compared to smectite. In addition vermiculite, as illite, presents an ordered distribution of interlayer cations which eases the structural characterization of the interlayer configuration as compared to smectite. ${ }^{49}$ The structural studies devoted to the configuration of interlayer species have led to different structure models that will be described below.

In bi-hydrated $\mathrm{Mg}$-vermiculite, $\mathrm{Mg}^{2+}$ cations are located in the mid-plane of the interlayer with one sheet of $\mathrm{H}_{2} \mathrm{O}$ molecules on each side of this plane (Type II - Figure 12). ${ }^{5,50,51,52,53}$ According to this model, $\mathrm{Mg}$ is octahedrally coordinated by six $\mathrm{H}_{2} \mathrm{O}$ molecules

544 whereas additional $\mathrm{H}_{2} \mathrm{O}$ molecules, which are weakly bound to the cation, are located on the 545 same plane as the six cation-bound $\mathrm{H}_{2} \mathrm{O}$ molecules. ${ }^{54-57}$ A Type II configuration of $\mathrm{H}_{2} \mathrm{O}$ 546 molecules was also proposed for Na-saturated vermiculite, ${ }^{58,59}$ and for Na-, Ca- and Li-rich 547 altered phlogopites. ${ }^{60}$

548 A second configuration of interlayer species has been proposed for Ca-saturated 549 vermiculites (Type III - Figure 12). ${ }^{58,61,62}$ In this model, two distinct coordinations are 550 reported for $\mathrm{Ca}^{2+}$ cations, two out of three $\mathrm{Ca}^{2+}$ cations being octahedrally coordinated as in 551 type II configuration, whereas remaining $\mathrm{Ca}^{2+}$ cations exhibit a cubic coordination. This dual 552 coordination induces the presence of two discrete planes of $\mathrm{H}_{2} \mathrm{O}$ molecules (planes 2 and 3 553 Figure 12) in addition to that observed in the type II configuration, which holds most $\mathrm{H}_{2} \mathrm{O}$ 554 molecules (plane 1 - Figure 12). The increased heterogeneity of $\mathrm{H}_{2} \mathrm{O}$ configuration in Ca-, 555 Sr-, and Ba-saturated samples as compared to Mg-saturated ones was confirmed both from 556 diffraction and IR results. ${ }^{56,57}$ A Type III configuration of $\mathrm{H}_{2} \mathrm{O}$ molecules was also proposed 557 for Na-saturated vermiculite. ${ }^{58}$ Figure 13 compares the $2 \mathrm{WG}$ configuration of interlayer $\mathrm{H}_{2} \mathrm{O}$ 558 molecules determined for Ca-SWy-2 $(40 \% \mathrm{RH})$ in the present study with that reported in the 559 literature for Ca-saturated vermiculite. ${ }^{58,61}$ After normalization of the three distributions to the 560 denser plane of $\mathrm{H}_{2} \mathrm{O}$ molecules, the three planes of $\mathrm{H}_{2} \mathrm{O}$ molecules appear closely related to 
the $2 \mathrm{WG}$ configuration proposed in the present study to describe the positional distribution of interlayer species.

To compare the $\Delta \mathrm{d}$ values obtained in the present study with those reported in the

564 literature (1.14-1.45 - Table 4), these values can be normalized to the thickness of the interlayer space to account better for the balance of the interactions with the interlayer cation on the one hand and the 2:1 layer on the other hand (Table 5). Following such a normalization procedure, the $\Delta \mathrm{d}$ values determined for the $2 \mathrm{WG}$ configuration of $\mathrm{H}_{2} \mathrm{O}$ molecules are consistent with those reported in the literature whereas lower values are obtained when assuming a 2WS configuration.

In addition, z-coordinates along $\mathrm{c}^{*}$ axis were recalculated together with typical distances between the 2:1 layer and the planes of $\mathrm{H}_{2} \mathrm{O}$ molecules, and between $\mathrm{H}_{2} \mathrm{O}$ molecules and interlayer cations (Table 4). For type II and III configurations the distance between the 2:1 layer and the densest plane of $\mathrm{H}_{2} \mathrm{O}$ molecules scatters between $2.36 \AA$ and $2.82 \AA$ and is 574 consistent with the formation of $\mathrm{H}$-bonds between interlayer $\mathrm{H}_{2} \mathrm{O}$ molecules and the clay framework. The distance between the densest plane of $\mathrm{H}_{2} \mathrm{O}$ molecules and the interlayer cation ranges from 1.14-1.45 $\AA$.

578 third configuration of water in $2 \mathrm{~W}$ smectite has been envisaged for Na-beidellite samples, 579 with $\mathrm{Na}^{+}$cations being partly engaged in the ditrigonal cavities of the 2:1 layers and the coordinated $\mathrm{H}_{2} \mathrm{O}$ molecules distributed on either side of the interlayer mid-plane which is 581 devoid of atoms (Type IV - Figure 12). ${ }^{12,13,63}$ Such a migration of the interlayer cation from 582 the interlayer mid-plane toward the 2:1 clay framework is consistent with MC simulations and 583 IR spectroscopy results which both support the formation of inner-sphere complexes for 584 monovalent cations in tetrahedrally substituted $2: 1$ phyllosilicates..$^{21,24,26,31}$ In the present study, similar distributions of interlayer species have been determined whatever the location 
of the layer charge deficit in agreement with previous reports of Type II and Type III

587 configurations of interlayer species in tetrahedrally substituted $2 \mathrm{~W}$ vermiculites. ${ }^{58-60}$ The central location of $\mathrm{Na}^{+}$cations was found to be consistent with experimental XRD data even when $\mathrm{Na}^{+}$cations account for a significant part of the interlayer electronic density $(13 \%$ of the

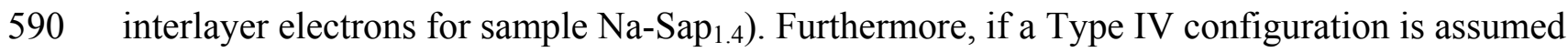

591 for the distribution of interlayer species, significant discrepancies arise between experimental 592 and calculated patterns, especially for the 002 and 003 reflections which are extremely sensitive to the presence of interlayer species at the interlayer mid-plane position (Figure 14). In conclusion, the present data does not provide experimental evidence for the migration of monovalent cations toward the surface of tetrahedrally substituted 2:1 layers.

\section{Acknowledgments}

The results presented are a part of a Ph.D. thesis granted by Andra (French National Agency for Nuclear Waste Disposal). Andra is thanked for the permission to publish this

600 manuscript and for financial support. BL acknowledges financial support from the 601 CNRS/PICS709 program, and from the CNRS/SdU "postes rouges" fellowships granted to BAS. VAD and BAS are grateful to the Russian Science Foundation for partial financial support. Laurent Michot (LEM, Nancy - France) is thanked for the fruitful discussions about

604 smectite hydration. Jean-Louis Robert (IST Orléans, France) kindly provided the synthetic 605 saponite samples.

606 
(1) Moore, D. M.; Reynolds, R. C., Jr X-ray Diffraction and the Identification and 610 Analysis of Clay Minerals; Oxford University Press: Oxford and New York, 1997.

611

612

613

614

615

616

617

618

619

620

621

622

623

624

625

626

627

628

629

630

631

632

633

(2) Nagelschmidt, G. Z. Kristallogr. 1936, 93, 481-487.

(3) Bradley, W. F.; Grim, R. E.; Clark, G. F. Z. Kristallogr. 1937, 97, 260-270.

(4) Mooney, R. W.; Keenan, A. G.; Wood, L. A. J. Am. Chem. Soc. 1952, 74,

1371-1374.

(5) Walker, G. F. Clays \& Clay Miner. 1956, 4, 101-115.

(6) Norrish, K. Discuss. Faraday Soc. 1954, 18, 120-133.

(7) Van Olphen, H. J. Colloid Sci. 1965, 20, 822-837.

(8) Kittrick, J. A. Soil Sci. Soc. Am. J. 1969a, 33, 217-222.

(9) Kittrick, J. A. Soil Sci. Soc. Am. J. 1969b, 33, 222-225.

(10) Laird, D. A. Clays \& Clay Miner. 1996, 44, 553-559.

(11) Laird, D. A. Clays \& Clay Miner. 1999, 47, 630-636.

(12) Ben Brahim, J.; Besson, G.; Tchoubar, C. In 5th Meeting of the European Clay Groups: Prague, 1983, pp 65-75.

(13) Ben Brahim, J.; Besson, G.; Tchoubar, C. J. Appl. Cryst. 1984, 17, 179-188.

(14) Bérend, I.; Cases, J. M.; François, M.; Uriot, J. P.; Michot, L. J.; Masion, A.; Thomas, F. Clays \& Clay Miner. 1995, 43, 324-336.

(15) Cases, J. M.; Bérend, I.; Besson, G.; François, M.; Uriot, J. P.; Thomas, F.; Poirier, J. P. Langmuir 1992, 8, 2730-2739.

(16) Cases, J. M.; Bérend, I.; François, M.; Uriot, J. P.; Michot, L. J.; Thomas, F. Clays \& Clay Miner. 1997, 45, 8-22.

(17) Cuadros, J. Amer. J. Sci. 1997, 297, 829-841.

(18) Ferrage, E.; Lanson, B.; Sakharov, B. A.; Drits, V. A. Amer. Mineral. 2005, in press Ms \#1776R. 
635

636

637

638

639

640

641

642

643

644

645

646

647

648

649

650

651

652

653

654

655

656

657

Mineral. 2005, in preparation.

(20) Ferrage, E.; Tournassat, C.; Rinnert, E.; Lanson, B. Geochim. Cosmochim. Acta 2005, in press Ms \#2963.

(21) Skipper, N. T.; Chang, F. R. C.; Sposito, G. Clays \& Clay Miner. 1995, 43, 285-293.

(22) Chang, F. R. C.; Skipper, N. T.; Sposito, G. Langmuir 1998, 14, 1201-1207.

(23) Boek, E. S.; Coveney, P. V.; Skipper, N. T. J. Am. Chem. Soc. 1995, 117, 12608-12617.

(24) Chang, F. R. C.; Skipper, N. T.; Sposito, G. Langmuir 1995, 11, 2734-2741.

(25) Chang, F. R. C.; Skipper, N. T.; Sposito, G. Langmuir 1997, 13, 2074-2082.

(26) Skipper, N. T.; Sposito, G.; Chang, F. R. C. Clays \& Clay Miner. 1995, 43, 294-303.

(27) Skipper, N. T.; Refson, K.; McConnell, J. D. C. J. Chem. Phys. 1991, 94, 74347445 .

(28) Greathouse, J.; Refson, K.; Sposito, G. J. Am. Chem. Soc. 2000, 122, 1145911464.

(29) Sposito, G.; Skipper, N. T.; Sutton, R.; Park, S. H.; Soper, A. K.; Greathouse, J. A. Proc. Nat. Acad. Sci. USA 1999, 96, 3358-3364.

(30) Michot, L. J.; Villiéras, F. Clay Miner. 2002, 37, 39-57.

(31) Pelletier, M.; Michot, L. J.; Humbert, B.; Barres, O.; D'espinose de la Callerie, J. B.; Robert, J. L. Amer. Mineral. 2003, 88, 1801-1808.

(32) Drits, V. A.; Sakharov, B. A. X-Ray structure analysis of mixed-layer minerals; Dokl. Akad. Nauk SSSR: Moscow, 1976. 
659

660

661

662

663

664

665

666

667

668

669

670

671

672

673

674

675

676

677

678

679

680

681

33, 351-371.

(34) Sakharov, B. A.; Lindgreen, H.; Salyn, A.; Drits, V. A. Clays \& Clay Miner. 1999, 47, 555-566.

(35) Drits, V. A.; Srodon, J.; Eberl, D. D. Clays \& Clay Miner. 1997, 45, 461-475.

(36) Guinier, A. Théorie et technique de la radiocristallographie; Dunod: Paris, 1964.

(37) Drits, V. A.; Tchoubar, C. X-ray diffraction by disordered lamellar structures:

Theory and applications to microdivided silicates and carbons; Springer-Verlag: Berlin, 1990.

(38) Howard, S. A.; Preston, K. D. In Modern Powder Diffraction; Bish, D. L., Post, J. E., Eds.; Mineralogical Society of America: Wahington D.C., 1989; Reviews in Mineralogy Vol. 20, pp 217-275.

(39) Plançon, A. Amer. Mineral. 2002, 87, 1672-1677.

(40) Marry, V., Ph.D. dissertation, Pierre et Marie Curie University - Paris, 2002.

(41) Marry, V.; Turq, P.; Cartailler, T.; Levesque, D. J. Chem. Phys. 2002, 117, 3454-3463.

(42) Delville, A. Langmuir 1992, 8, 1796-1805.

(43) Boek, E. S.; Coveney, P. V. ; Skipper, N. T. Langmuir 1995, 11, 4629-4631.

(44) Lipson, H. In International tables for X-ray crystallography;; Casper, J. S., Lonsdale, K., Eds., 1967; International Union of Crystallography; Mathematical tables Vol. 2 - Mathematical tables, pp 235-315.

(45) Sposito, G.; Prost, R. Chem. Rev. 1982, 82, 553-573.

(46) Bailey, S. W. Clay Miner. 1980, 15, 85-93. 
(47) Calle, C. de la; Suquet, H. In Hydrous Phyllosilicates (exclusive of micas);

683 Bailey, S. W., Ed.; Mineralogical Society of America: Washington, D.C., 1988; Reviews in 684 Mineralogy Vol. 19, pp 455-496.

685

686

687

688

689

690

691

692

693

694

695

696

697

698411.

699

700

701

702

703

704

705

136.
(48) Walker, G. F. Clay Miner. Bull. 1958, 3, 302-313.

(49) Besson, G.; Misfud, A.; Tchoubar, C.; Méring, J. Clays \& Clay Miner. 1974, 22, 379-384.

(50) Mathieson, A. M.; Walker, G. F. Amer. Mineral. 1954, 39, 231-255.

(51) Mathieson, A. M. Amer. Mineral. 1958, 43, 216-227.

(52) Bradley, W. F.; Serratosa, J. M. In Clays \& Clay Minerals, Proceeding of the 7th Clay Conference; Pergamon Press, 1960, pp 260-270.

(53) Shirozu, H.; Bailey, S. W. Amer. Mineral. 1966, 51, 1124-1143.

(54) Alcover, J. F.; Gatineau, L.; Méring, J. Clays \& Clay Miner. 1973, 21, 131-

(55) Alcover, J. F.; Gatineau, L. Clay Miner. 1980, 15, 25-35.

(56) Alcover, J. F.; Gatineau, L. Clay Miner. 1980, 15, 239-248.

(57) Fornés, V.; Calle, C. de la; Suquet, H.; Pezerat, H. Clay Miner. 1980, 15, 399-

(58) Slade, P. G.; Stone, P. A.; Radoslovitch, E. W. Clays \& Clay Miner. 1985, 33, $51-61$.

(59) Beyer, J.; Graf von Reichenbach, H. Clay Miner. 2002, 37, 157-168.

(60) Le Renard, J.; Mamy, J. Bull. Groupe Franç. Argiles 1971, 23, 119-127.

(61) Calle, C. de la; Pezerat, H.; Gasperin, M. J. Phys. 1977, C7, 128-133.

(62) Calle, C. de la; Suquet, H.; Dubernat, J.; Pezerat, H. Clay Miner. 1978, 13, 275-197. 
(63) Ben Brahim, J.; Armagan, N.; Besson, G.; Tchoubar, C. J. Appl. Cryst. 1983,

$707 \quad 16,264-269$. 
710 Figure 1. Comparison between experimental and calculated XRD patterns for the Ca-

711 saturated SWy-1 montmorillonite sample recorded at 80\% RH. Structural parameters used for

712 the calculations are listed in Tables 1, 2, and 3. Experimental data are shown as crosses

713 whereas calculated profiles are shown as solid lines. Solid arrows indicate a significant misfit

714 between experimental and calculated patterns, whereas gray and open arrows indicate poor

715 and good fits, respectively. $00 \ell$ reflections are indexed in parentheses. (a) Calculation for a

716 periodic bi-hydrated structure (layer thickness of $2 \mathrm{~W}$ layers $=15.48 \AA$ ) assuming the usual

717 configuration of $\mathrm{H}_{2} \mathrm{O}$ molecules. ${ }^{1}$ (b) Calculation for a periodic bi-hydrated structure (layer

718 thickness of $2 \mathrm{~W}$ layers: $15.48 \AA$ ) assuming a 2WS configuration (see text for details) with

$719 \mathrm{~B}_{\text {wat }}=2 \AA^{2}$ for $\mathrm{H}_{2} \mathrm{O}$ molecules. ${ }^{18}$ (c) Calculation performed accounting for hydration

720 heterogeneities and assuming a $2 \mathrm{WS}$ configuration with $\mathrm{B}_{\text {wat }}=2 \AA^{2}$ for $\mathrm{H}_{2} \mathrm{O}$ molecules. ${ }^{18}$

721 Hydration heterogeneity was described by assuming the coexistence of a major MLS

722 containing $2 \mathrm{~W}$ and $1 \mathrm{~W}$ layers (95:5 ratio) and of a second structure containing the three layer

723 types $(2 \mathrm{~W}: 1 \mathrm{~W}: 0 \mathrm{~W}=85: 13: 2)$ in a 61:39 ratio (Table 2$)$. (d) Calculation performed

724 accounting for hydration heterogeneities and assuming a $2 \mathrm{WS}$ configuration with $\mathrm{B}_{\mathrm{wat}}=11 \AA^{2}$

725 for $\mathrm{H}_{2} \mathrm{O}$ molecules. (e) Calculation performed accounting for hydration heterogeneities and

726 assuming a $2 \mathrm{WG}$ configuration (see text for details).

727 Figure 2. Relative intensities of $00 \ell$ reflections, after normalization to the 001 reflection, as a

728 function of structural parameters specific to the $2 \mathrm{WG}$ configuration (see text for details). The

729 total amount of $\mathrm{H}_{2} \mathrm{O}$ molecules $\left(\mathrm{nH}_{2} \mathrm{O}\right)$ is given per $\mathrm{O}_{20}(\mathrm{OH})_{4}$, whereas the full width at half

730 maximum intensity (FWHM) of the distribution and the distance, in projection along the $\mathrm{c}^{*}$

731 axis, from its maximum to the interlayer mid-plane $(\Delta d)$ are given in $\AA$. 
Figure 3. Comparison between experimental and calculated XRD patterns for the $\mathrm{Ca}$ -

733 saturated SWy-2 montmorillonite sample recorded at 40\% RH. Structural parameters used for 734 the calculations are listed in Tables 1, 2, and 3. Patterns as for Figure 1. * indicates hk bands, 735 whereas vertical ticks denote the presence of accessory quartz reflections. (a) Calculation 736 performed assuming a $2 \mathrm{WS}$ configuration with $\mathrm{B}_{\text {wat }}=2 \AA^{2}$ for $\mathrm{H}_{2} \mathrm{O}$ molecules. ${ }^{18}$ (b)

737 Calculation performed assuming a 2WS configuration with $\mathrm{B}_{\text {wat }}=11 \AA^{2}$ for $\mathrm{H}_{2} \mathrm{O}$ molecules.

738 (c) Calculation performed assuming a $2 \mathrm{WG}$ configuration.

739 Figure 4. Comparison between experimental and calculated XRD patterns for the Sr-saturated 740 SWy-1 montmorillonite sample recorded at $60 \%$ RH. Structural parameters used for the 741 calculations are listed in Tables 1, 2, and 3. Patterns as for Figure 1. (a) Calculation performed 742 assuming a 2WS configuration with $\mathrm{B}_{\text {wat }}=2 \AA^{2}$ for $\mathrm{H}_{2} \mathrm{O}$ molecules. ${ }^{18}$ (b) Calculation 743 performed assuming a 2WS configuration with $\mathrm{B}_{\text {wat }}=11 \AA^{2}$ for $\mathrm{H}_{2} \mathrm{O}$ molecules. (c) 744 Calculation performed assuming a 2WG configuration.

745 Figure 5. Comparison between experimental and calculated XRD patterns for the Sr-saturated 746 SWy-1 montmorillonite sample recorded at $80 \%$ RH. Structural parameters used for the 747 calculations are listed in Tables 1, 2, and 3. Patterns as for Figure 1. (a) Calculation performed 748 assuming a 2WS configuration with $\mathrm{B}_{\text {wat }}=2 \AA^{2}$ for $\mathrm{H}_{2} \mathrm{O}$ molecules. ${ }^{18}$ (b) Calculation 749 performed assuming a $2 \mathrm{WS}$ configuration with $\mathrm{B}_{\text {wat }}=11 \AA^{2}$ for $\mathrm{H}_{2} \mathrm{O}$ molecules. (c) 750 Calculation performed assuming a $2 \mathrm{WG}$ configuration.

751 Figure 6. Comparison between experimental and calculated XRD patterns for the Na752 saturated SWy-2 montmorillonite sample recorded at $80 \%$ RH. Structural parameters used for 753 the calculations are listed in Tables 1, 2, and 3. Patterns as for Figures 1 and 3. (a) Calculation 754 performed assuming a $2 \mathrm{WS}$ configuration with $\mathrm{B}_{\text {wat }}=2 \AA^{2}$ for $\mathrm{H}_{2} \mathrm{O}$ molecules. ${ }^{18}$ (b) 755 Calculation performed assuming a 2WS configuration with $\mathrm{B}_{\text {wat }}=11 \AA^{2}$ for $\mathrm{H}_{2} \mathrm{O}$ molecules. 756 (c) Calculation performed assuming a 2WG configuration. (d) Calculation performed 
assuming the distribution of interlayer species derived from MC simulations using the NVT ensemble and shown in Figure 7.

Figure 7. Density profiles of interlayer species along the $\mathrm{c}^{*}$ axis derived from MC simulations performed using the NVT ensemble. z-coordinates are given in $\AA$ with the origin

761 located in the interlayer mid-plane. Solid, dashed and gray lines represent $\mathrm{O}, \mathrm{H}$, and $\mathrm{Na}^{+}$ 762 atoms, respectively.

763 Figure 8. Comparison between experimental and calculated XRD patterns for the Nasaturated $\mathrm{Sap}_{0.8}$ saponite sample recorded at $90 \% \mathrm{RH}$. Structural parameters used for the

765 calculations are listed in Tables 1, 2, and 3. Patterns as for Figure 1. (a) Calculation performed 766 assuming a $2 \mathrm{WS}$ configuration with $\mathrm{B}_{\mathrm{wat}}=2 \AA^{2}$ for $\mathrm{H}_{2} \mathrm{O}$ molecules. ${ }^{18}$ (b) Calculation

767 performed assuming a $2 \mathrm{WS}$ configuration with $\mathrm{B}_{\text {wat }}=11 \AA^{2}$ for $\mathrm{H}_{2} \mathrm{O}$ molecules. (c)

768 Calculation performed assuming a 2WG configuration. (d) Calculation performed assuming a $7692 \mathrm{WS}$ configuration with $\mathrm{B}_{\text {wat }}=30 \AA^{2}$ for $\mathrm{H}_{2} \mathrm{O}$ molecules, $10.5 \mathrm{nH}_{2} \mathrm{O}$ molecules per $\left.\mathrm{O}_{20}(\mathrm{OH})_{2}\right)$ $770 \quad$ in $2 \mathrm{~W}$ layers, and $\Delta \mathrm{d}=1.38 \AA$.

771 Figure 9. Comparison between experimental and calculated XRD patterns for the Na-

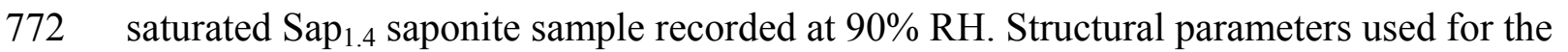
773 calculations are listed in Tables 1, 2, and 3. Patterns as for Figure 1. (a) Calculation performed 774 assuming a $2 \mathrm{WS}$ configuration with $\mathrm{B}_{\text {wat }}=2 \AA^{2}$ for $\mathrm{H}_{2} \mathrm{O}$ molecules. ${ }^{18}$ (b) Calculation 775 performed assuming a $2 \mathrm{WS}$ configuration with $\mathrm{B}_{\text {wat }}=11 \AA^{2}$ for $\mathrm{H}_{2} \mathrm{O}$ molecules. (c) 776 Calculation performed and assuming a 2WG configuration.

777 Figure 10. Comparison between experimental XRD patterns and those calculated assuming 778 the usual configuration of $\mathrm{H}_{2} \mathrm{O}$ molecules. ${ }^{1}$ Hydration heterogeneity has been taken into 779 account for all calculations. Structural parameters used for the calculations are listed in Table 780 1. Patterns as for Figures 1 and 3. (a) Ca-saturated SWy-1 montmorillonite sample recorded at $78180 \%$ RH. (b) Ca-saturated SWy-2 montmorillonite sample recorded at 40\% RH. (c) Sr- 
saturated SWy-1 montmorillonite sample recorded at 60\% RH. (d) Sr-saturated SWy-1 montmorillonite sample recorded at $80 \% \mathrm{RH}$. (e) Na-saturated SWy-2 montmorillonite sample recorded at $80 \%$ RH. (f) Na-saturated $\mathrm{Sap}_{0.8}$ saponite sample recorded at $90 \% \mathrm{RH}$. (g)

Na-saturated $\mathrm{Sap}_{1.4}$ saponite sample recorded at $90 \% \mathrm{RH}$.

Figure 11. Density profiles along the $\mathrm{c}^{*}$ axis of the electron distribution in the interlayer of bi-hydrated smectite layers. z-coordinates are given in $\AA$ with the origin located in the interlayer mid-plane. (a) Comparison between the electron distribution derived from the density profiles of interlayer species calculated using the NVT ensemble (Figure 7) and the one determined from XRD profile modeling for the Na-SWy-2 montmorillonite sample (80\% $\mathrm{RH})$. (b) Comparison between the electron distributions determined from XRD profile modeling for the two Ca-saturated montmorillonite samples under different $\mathrm{RH}$ conditions. (c) Comparison between the electron distributions determined from XRD profile modeling for the two Sr-saturated SWy-1 montmorillonite samples under different RH conditions. (d) Comparison between the electron distributions determined from XRD profile modeling for the two Na-saturated synthetic saponite samples with different amounts of layer charge.

Figure 12. Schematic description of the different configurations proposed in the literature for interlayer species in $2 \mathrm{~W}$ smectite layers. $\mathrm{O}$ and $\mathrm{T}$ refer to the octahedral and tetrahedral sheets of the 2:1 layer, respectively. Labels of the different sheets of $\mathrm{H}_{2} \mathrm{O}$ molecules are detailed in the text.

Figure 13. Comparison of the distributions of $\mathrm{H}_{2} \mathrm{O}$ molecules reported for bi-hydrated smectites. The distributions are normalized to the denser plane of $\mathrm{H}_{2} \mathrm{O}$ molecules, and zcoordinates are given in fraction of the interlayer with the origin located in the interlayer midplane after normalization to the interlayer thickness. The distribution determined from XRD profile modeling for the Ca-saturated SWy-2 montmorillonite sample $(40 \% \mathrm{RH})$ is plotted as 
806 a solid line, whereas data from De la Calle et al. and from Slade et al. are shown as dashed

807 and dotted-dashed lines, respectively. ${ }^{58,61}$

808 Figure 14. Comparison between experimental and calculated XRD patterns for the Na-

809 saturated $\mathrm{Sap}_{1.4}$ saponite sample recorded at $90 \%$ RH. Structural parameters used for the

810 calculations are listed in Tables 1, 2, and 3. Patterns as for Figure 1. Calculation is performed

811 assuming a Type IV configuration of interlayer species with a shift of the interlayer cation

812 from the interlayer mid-plane toward the $2: 1$ clay framework. $^{13}$

813 
Table 1. Optimum structural parameters used for the simulation of experimental XRD

profiles.

\begin{tabular}{|c|c|c|c|c|c|c|c|c|c|c|c|}
\hline Sample & $\begin{array}{l}\text { Rel. } \\
\text { ab. } \\
(\%)^{\mathrm{a}}\end{array}$ & $2 W^{b}$ & $1 \mathrm{~W}^{\mathrm{b}}$ & $0 \mathrm{~W}^{\mathrm{b}}$ & $\begin{array}{c}\text { L. } \\
\text { Tck. } \\
2 W^{c}\end{array}$ & $\begin{array}{c}\text { L. } \\
\text { Tck. } \\
1 \mathrm{~W}^{\mathrm{c}} \\
\end{array}$ & $\begin{array}{c}\text { L. } \\
\text { Tck. } \\
0 W^{\mathrm{c}} \\
\end{array}$ & $\begin{array}{l}\mathrm{nH}_{2} 0 \\
1 \mathrm{~W}^{\mathrm{d}}\end{array}$ & $\mathrm{N}^{\mathrm{e}}$ & $\sigma^{* f}$ & $\sigma_{z}^{g}$ \\
\hline \multirow[b]{2}{*}{$\begin{array}{l}\text { Ca-SWy-2 } \\
(40 \% \text { RH })^{\mathrm{h}}\end{array}$} & 87 & 100 & 0 & 0 & \multirow[b]{2}{*}{15.18} & \multirow[b]{2}{*}{12.60} & \multirow[b]{2}{*}{10.00} & \multirow[b]{2}{*}{3.2} & \multirow[b]{2}{*}{8.7} & \multirow[b]{2}{*}{6.5} & \multirow[b]{2}{*}{0.35} \\
\hline & 13 & 60 & 30 & 10 & & & & & & & \\
\hline \multirow{2}{*}{$\begin{array}{l}\text { Ca-SWy-1 } \\
(80 \% \text { RH })^{\mathrm{i}}\end{array}$} & 61 & 95 & 5 & 0 & \multirow{2}{*}{15.51} & \multirow{2}{*}{12.85} & \multirow{2}{*}{10.00} & \multirow{2}{*}{3.3} & \multirow{2}{*}{6.0} & \multirow{2}{*}{6.5} & \multirow{2}{*}{0.27} \\
\hline & 39 & 85 & 13 & 2 & & & & & & & \\
\hline \multirow{2}{*}{$\begin{array}{l}\text { Sr-SWy-1 } \\
(60 \% \text { RH })^{i}\end{array}$} & 82 & 100 & 0 & 0 & \multirow{2}{*}{15.53} & \multirow{2}{*}{12.58} & \multirow{2}{*}{10.00} & \multirow{2}{*}{3.5} & \multirow{2}{*}{7.5} & \multirow{2}{*}{5.5} & \multirow{2}{*}{0.35} \\
\hline & 18 & 75 & 15 & 10 & & & & & & & \\
\hline \multirow{2}{*}{$\begin{array}{l}\text { Sr-SWy-1 } \\
(80 \% \text { RH })^{i}\end{array}$} & 84 & 100 & 0 & 0 & \multirow{2}{*}{15.73} & \multirow{2}{*}{12.70} & \multirow{2}{*}{10.00} & \multirow{2}{*}{5.5} & \multirow{2}{*}{7.5} & \multirow{2}{*}{5.5} & \multirow{2}{*}{0.35} \\
\hline & 16 & 75 & 15 & 10 & & & & & & & \\
\hline \multirow{2}{*}{$\begin{array}{c}\text { Na-SWy-2 } \\
(80 \% \text { RH) }\end{array}$} & 90 & 96 & 2 & 2 & \multirow{2}{*}{15.52} & \multirow{2}{*}{12.55} & \multirow{2}{*}{9.60} & & & & \\
\hline & 10 & 60 & 30 & 10 & & & & 3.2 & 0.2 & 11.0 & 0.20 \\
\hline $\mathrm{Na}-\mathrm{Sap}_{0.8}$ & 44 & 100 & 0 & 0 & 1540 & 1320 & 980 & 57 & 130 & 20 & 019 \\
\hline$(30 / 0 \mathrm{~N})$ & 56 & 90 & 5 & 5 & & & & & & & \\
\hline $\mathrm{Na} \mathrm{Sap}_{1.4}$ & 91 & 100 & 0 & 0 & 500 & 1200 & $0 \Omega 0$ & 50 & 10 & & \\
\hline$(90 \% \mathrm{RH})$ & 9 & 70 & 20 & 10 & & & & & & & \\
\hline
\end{tabular}

${ }^{a}$ Relative proportion of the different contributions to the diffracted intensity. ${ }^{b}$ Relative proportion of the different layer types in the different contributions to the diffracted intensity. $2 \mathrm{~W}, 1 \mathrm{~W}$, and $0 \mathrm{~W}$ stand for bi-hydrated, mono-hydrated and de-hydrated smectite layers, respectively. ${ }^{\mathrm{c}}$ Layer thickness (L. Tck.) of the different layer types. ${ }^{\mathrm{d}}$ Number of $\mathrm{H}_{2} \mathrm{O}$ molecules in $1 \mathrm{~W}$ layers (per $\mathrm{O}_{20}(\mathrm{OH})_{4}$ ). ${ }^{\mathrm{e}}$ Mean thickness of the coherent scattering domain size along the $\mathrm{c}^{*}$ axis (in layers). ${ }^{\mathrm{f}}$ Sigmastar parameter characterizing the sample orientation (in $\left.{ }^{\circ}\right) .{ }^{1 \mathrm{~g}}$ Standard deviation of the layer thickness parameter (in $\AA$ ) ${ }^{18}{ }^{\mathrm{h}}$ Data from Ferrage et al. ${ }^{20}{ }^{\mathrm{i}}$ Data from Ferrage et al. ${ }^{18}$ 
Table 2. Structural parameters of the interlayer space determined from XRD profile modeling as a function of the assumed water configuration.

\begin{tabular}{|c|c|c|c|c|c|c|c|}
\hline \multirow{2}{*}{ Sample } & \multicolumn{2}{|c|}{$2 \mathrm{WS}, \mathrm{B}_{\mathrm{wat}}=2^{\mathrm{a}}$} & \multicolumn{2}{|c|}{$2 \mathrm{WS}, \mathrm{B}_{\mathrm{wat}}=11^{\mathrm{a}}$} & \multicolumn{3}{|c|}{$2 \mathrm{WG}^{\mathrm{b}}$} \\
\hline & $\mathrm{nH}_{2} 0^{\mathrm{c}}$ & $\Delta \mathrm{d}^{\mathrm{d}}$ & $\mathrm{nH}_{2} \mathrm{O}$ & $\Delta \mathrm{d}$ & $\mathrm{nH}_{2} \mathrm{O}$ & $\Delta \mathrm{d}$ & $\mathrm{FWHM}^{\mathrm{e}}$ \\
\hline Ca-SWy-2 (40\%RH) & 6.2 & 1.20 & 6.6 & 1.30 & 7.8 & 1.34 & 1.4 \\
\hline Ca-SWy-1 (80\%RH) & 6.6 & 1.20 & 6.8 & 1.32 & 10.0 & 1.37 & 1.7 \\
\hline Sr-SWy-1 (60\%RH) & 6.0 & 1.20 & 6.8 & 1.32 & 8.5 & 1.40 & 1.2 \\
\hline Sr-SWy-1 (80\%RH) & 6.0 & 1.20 & 7.0 & 1.41 & 9.5 & 1.52 & 1.5 \\
\hline Na-SWy-2 (80\%RH) & 7.4 & 1.20 & 8.2 & 1.41 & 9.5 & 1.50 & 1.4 \\
\hline $\mathrm{Na}^{-S_{a p}}{ }_{0.8}(90 \% \mathrm{RH})$ & 8.5 & 1.20 & 9.3 & 1.33 & 10.5 & 1.39 & 1.4 \\
\hline $\mathrm{Na}^{-S_{a p}}{ }_{1.4}(90 \% \mathrm{RH})$ & 8.4 & 1.20 & 9.0 & 1.33 & 9.4 & 1.35 & 0.8 \\
\hline
\end{tabular}

a 2 WS corresponds to an interlayer configuration of $\mathrm{H}_{2} \mathrm{O}$ molecules distributed as one plane on either side of the interlayer mid-plane. The Debye-Waller temperature factor for water $\left(B_{\text {wat }}\right)$ given in $\AA^{2} .{ }^{b} 2 \mathrm{WG}$ corresponds to an interlayer configuration of $\mathrm{H}_{2} \mathrm{O}$ molecules distributed according to a Gaussian function on either side of the interlayer mid-plane. ${ }^{\mathrm{c}}$ The number of $\mathrm{H}_{2} \mathrm{O}$ molecules is given per $\mathrm{O}_{20}(\mathrm{OH})_{4}$. In this case, $\mathrm{B}_{\text {wat }}=0 \AA^{2}$. ${ }^{\mathrm{d}}$ The distance, in projection along the $\mathrm{c}^{*}$ axis, between the interlayer mid-plane and the maximum density of the distribution of $\mathrm{H}_{2} \mathrm{O}$ molecules $(\Delta \mathrm{d})$ is given in $\AA$. ${ }^{\mathrm{e}}$ The width of the Gaussian distribution of interlayer $\mathrm{H}_{2} \mathrm{O}$ molecules (FWHM) is given in $\AA$. 
Table 3. Optimum amounts of $\mathrm{H}_{2} \mathrm{O}$ molecules determined from XRD profile modeling for the different configurations of interlayer species, and from water vapor adsorption/desorption isotherms.

\begin{tabular}{|c|c|c|c|c|c|}
\hline Sample & $\begin{array}{c}\text { Type I } \\
\text { configuration }^{\mathrm{a}}\end{array}$ & $\begin{array}{c}2 \mathrm{WS} \\
\mathrm{B}_{\mathrm{wat}}=2^{\mathrm{b}}\end{array}$ & $\begin{array}{c}2 \mathrm{WS} \\
\mathrm{B}_{\mathrm{wat}}=11^{\mathrm{b}}\end{array}$ & $2 \mathrm{WG}^{\mathrm{c}}$ & Ads./Des. ${ }^{d}$ \\
\hline Ca-SWy-2 (40\%RH) & $7.25^{\mathrm{e}}$ & 8.32 & 8.58 & 10.11 & $8.62 / 10.17$ \\
\hline Ca-SWy-1 (80\%RH) & 7.06 & 8.30 & 8.54 & 12.36 & $12.85 / 13.70$ \\
\hline Sr-SWy-1 (60\%RH) & 7.06 & 7.60 & 8.85 & 10.72 & $\begin{array}{c}7.87 / 9.29 \\
(10.70 / 11.90)\end{array}$ \\
\hline Sr-SWy-1 (80\%RH) & 7.14 & 7.69 & 8.95 & 12.09 & $\begin{array}{c}9.83 / 10.45 \\
(12.80 / 13.70)\end{array}$ \\
\hline Na-SWy-2 (80\%RH) & 7.04 & 9.27 & 10.24 & 11.82 & $10.50 / 13.10$ \\
\hline Na-Sap $0.8(90 \% R H)$ & 7.00 & 10.62 & 11.60 & 13.07 & $13.39 / 14.49^{\mathrm{f}}$ \\
\hline $\mathrm{Na}-\mathrm{Sap}_{1.4}(90 \% \mathrm{RH})$ & 6.96 & 10.45 & 11.19 & 11.62 & $14.23 / 17.18^{\mathrm{f}}$ \\
\hline \multicolumn{6}{|c|}{$\begin{array}{l}\text { a Interlayer configuration of } \mathrm{H}_{2} \mathrm{O} \text { molecules commonly used for the calculation XRD } \\
\text { profiles including } 2 \mathrm{~W} \text { layers. }{ }^{1} \text { b } 2 \mathrm{WS} \text { corresponds to an interlayer configuration of } \mathrm{H}_{2} \mathrm{O} \\
\text { molecules distributed as one plane on either side of the interlayer mid-plane. The Debye-Waller } \\
\text { temperature factor for water }\left(\mathrm{B}_{\text {wat }}\right) \text { given in } \AA^{2} .{ }^{c} 2 \mathrm{WG} \text { corresponds to an interlayer } \\
\text { configuration of } \mathrm{H}_{2} \mathrm{O} \text { molecules distributed according to a Gaussian function on either side of } \\
\text { the interlayer mid-plane. In this case, } \mathrm{B}_{\text {wat }}=0 \AA^{2} .{ }^{d} \text { Water amounts determined experimentally } \\
\text { from water vapor adsorption/desorption isotherms. Data are taken from Cases et al., }{ }^{16} \text { and from } \\
\text { Bérend et al. }{ }^{14} \text { for divalent and monovalent cations, respectively. }{ }^{\text {e }} \text { The water contents are given } \\
\text { in mmol of water per g of clay. }{ }^{f} \text { Personal communication from Laurent Michot (LEM, Nancy, } \\
\text { France). }\end{array}$} \\
\hline
\end{tabular}


Table 4. Structural parameters of the different configurations reported in the literature for interlayer water in bi-hydrated smectite layers.

Type I configuration ${ }^{\text {a }}$

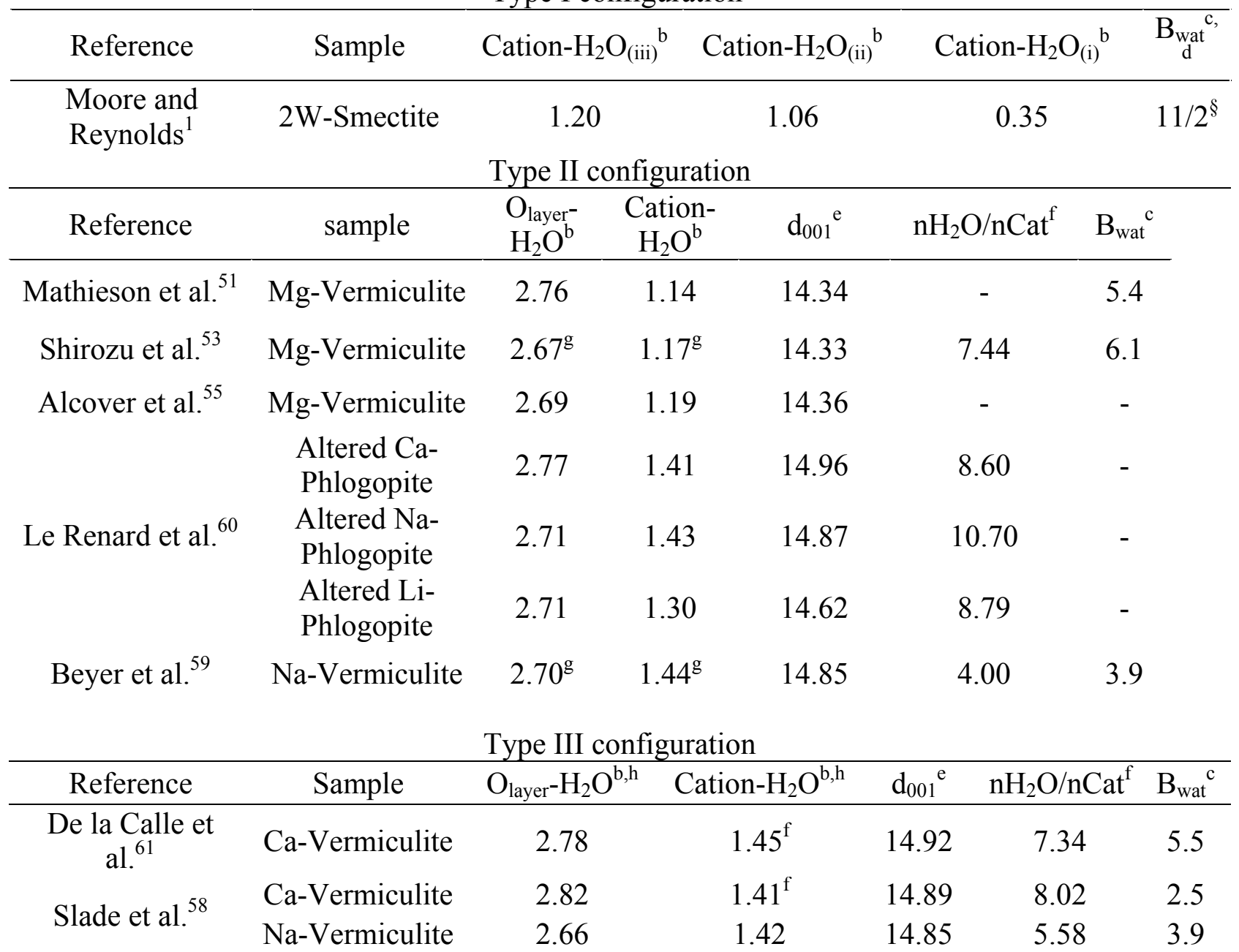

Type IV configuration

\begin{tabular}{cccccccc}
\hline Reference & Sample & $\begin{array}{c}\mathrm{O}_{\text {layer }} \\
\mathrm{H}_{2} \mathrm{O}^{\mathrm{b}}\end{array}$ & $\begin{array}{c}\mathrm{O}_{\text {layer }}^{-} \\
\text {Cation }^{\mathrm{b}}\end{array}$ & $\begin{array}{c}\text { Cation- } \\
\mathrm{H}_{2} \mathrm{O}^{\mathrm{b}}\end{array}$ & $\mathrm{d}_{001}{ }^{\mathrm{e}}$ & $\mathrm{nH}_{2} \mathrm{O} / \mathrm{nCat}^{\mathrm{f}}$ & $\mathrm{B}_{\text {wat }}{ }^{\mathrm{c}}$ \\
\hline $\begin{array}{c}\text { Ben Brahim et } \\
\text { al. }^{13}\end{array}$ & Na-Beidellite & 3.00 & 1.00 & 2.00 & 15.25 & 11.87 & 5
\end{tabular}

${ }^{a}$ Configurations of interlayer water in bi-hydrated smectite layers are schematized on Figure 2. ${ }^{b}$ Distances are measured in projection along the $\mathrm{c}^{*}$ axis and given in $\AA$. $\mathrm{O}_{\text {layer }}, \mathrm{H}_{2} \mathrm{O}$, and cation stand for the outermost plane of oxygen from the 2:1 layer, the $\mathrm{H}_{2} \mathrm{O}$ molecules and the interlayer cations, respectively. ${ }^{c} \mathrm{~B}_{\text {wat }}$ is the Debye-Waller temperature factor reported for $\mathrm{H}_{2} \mathrm{O}$ molecules (in $\AA^{2}$ ). ${ }^{\mathrm{d}}$ Debye-Waller factor is $11 \AA^{2}$ for plane (iii) and $2 \AA^{2}$ for planes (i) and (ii), respectively. ${ }^{\mathrm{e}}$ Basal distance $\mathrm{d}_{001}$ along the $\mathrm{c}^{*}$ axis is given in $\AA$. ${ }^{\mathrm{f}} \mathrm{nH}_{2} \mathrm{O} / \mathrm{nCat}$ represents the ratio between the number of interlayer $\mathrm{H}_{2} \mathrm{O}$ molecules and that of interlayer cations. ${ }^{\mathrm{g}}$ Average value for the different planes of $\mathrm{H}_{2} \mathrm{O}$ molecules. ${ }^{\mathrm{h}}$ Distances are given for the denser plane of $\mathrm{H}_{2} \mathrm{O}$ molecules. 
Table 5. Distances along the $\mathrm{c}^{*}$ axis between the interlayer mid-plane and the maximum density of the $\mathrm{H}_{2} \mathrm{O}$ molecule distribution normalized to the thickness of the interlayer space for the different configurations of interlayer species.

\begin{tabular}{|c|c|c|c|}
\hline Sample & $2 \mathrm{WS}, \mathrm{B}_{\mathrm{wat}}=2^{\mathrm{a}}$ & $2 \mathrm{WS}, \mathrm{B}_{\mathrm{wat}}=11^{\mathrm{a}}$ & $2 \mathrm{WG}^{\mathrm{b}}$ \\
\hline Ca-SWy-2 (40\%RH) & $27.8 \% \%^{\mathrm{c}}$ & $30.1 \%$ & $31.0 \%$ \\
\hline Ca-SWy-1 (80\%RH) & $26.8 \%$ & $29.4 \%$ & $30.5 \%$ \\
\hline Sr-SWy-1 (60\%RH) & $26.7 \%$ & $29.4 \%$ & $31.1 \%$ \\
\hline Sr-SWy-1 (80\%RH) & $26.1 \%$ & $30.7 \%$ & $33.1 \%$ \\
\hline Na-SWy-2 (80\%RH) & $26.7 \%$ & $31.4 \%$ & $33.4 \%$ \\
\hline Na-Sap $0.8(90 \% R H)$ & $27.1 \%$ & $30.0 \%$ & $31.4 \%$ \\
\hline Na-Sap $1.4(90 \% R H)$ & $28.4 \%$ & $31.4 \%$ & $31.9 \%$ \\
\hline Mean value & $27.1 \% \pm 0.7 \%$ & $30.3 \% \pm 0.8 \%$ & $31.8 \% \pm 1.0 \%$ \\
\hline \multicolumn{2}{|l|}{$\begin{array}{l}\text { Literature mean } \\
\text { value }^{\mathrm{d}}\end{array}$} & $32.7 \% \pm 2.1 \%$ & \\
\hline \multicolumn{4}{|c|}{$\begin{array}{l}\text { a } 2 \mathrm{WS} \text { corresponds to an interlayer configuration of } \mathrm{H}_{2} \mathrm{O} \text { molecules distributed as } \\
\text { plane on either side of the interlayer mid-plane. The Debye-Waller temperature } \\
\text { r for water }\left(\mathrm{B}_{\text {wat }}\right) \text { given in } \AA^{2} .{ }^{\mathrm{b}} 2 \mathrm{WG} \text { corresponds to an interlayer configuration of } \\
\text { molecules distributed according to a Gaussian function on either side of the } \\
\text { layer mid-plane. }{ }^{c} \text { The distance along the c* axis between the interlayer mid-plane } \\
\text { the maximum density of the } \mathrm{H}_{2} \mathrm{O} \text { molecule distribution }(\Delta \mathrm{d}) \text { is normalized to the } \\
\text { ness of the interlayer (L. Tck. minus the thickness of the } 2: 1 \text { layer }-6.54 \AA) \text {. } \\
\text { erage value calculated from the data reported for Type II and Type III configurations } \\
\text { terlayer species. }\end{array}$} \\
\hline
\end{tabular}




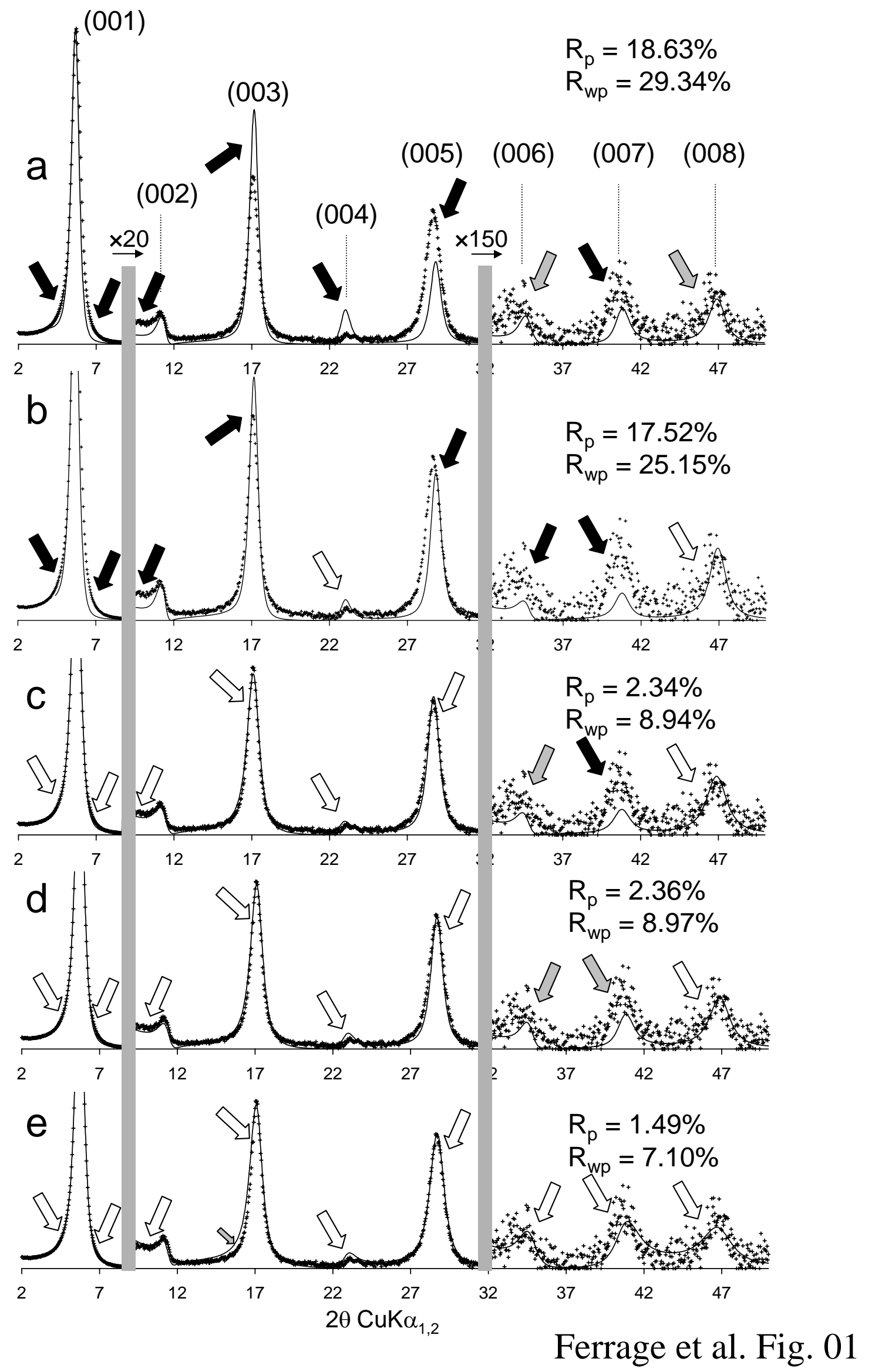



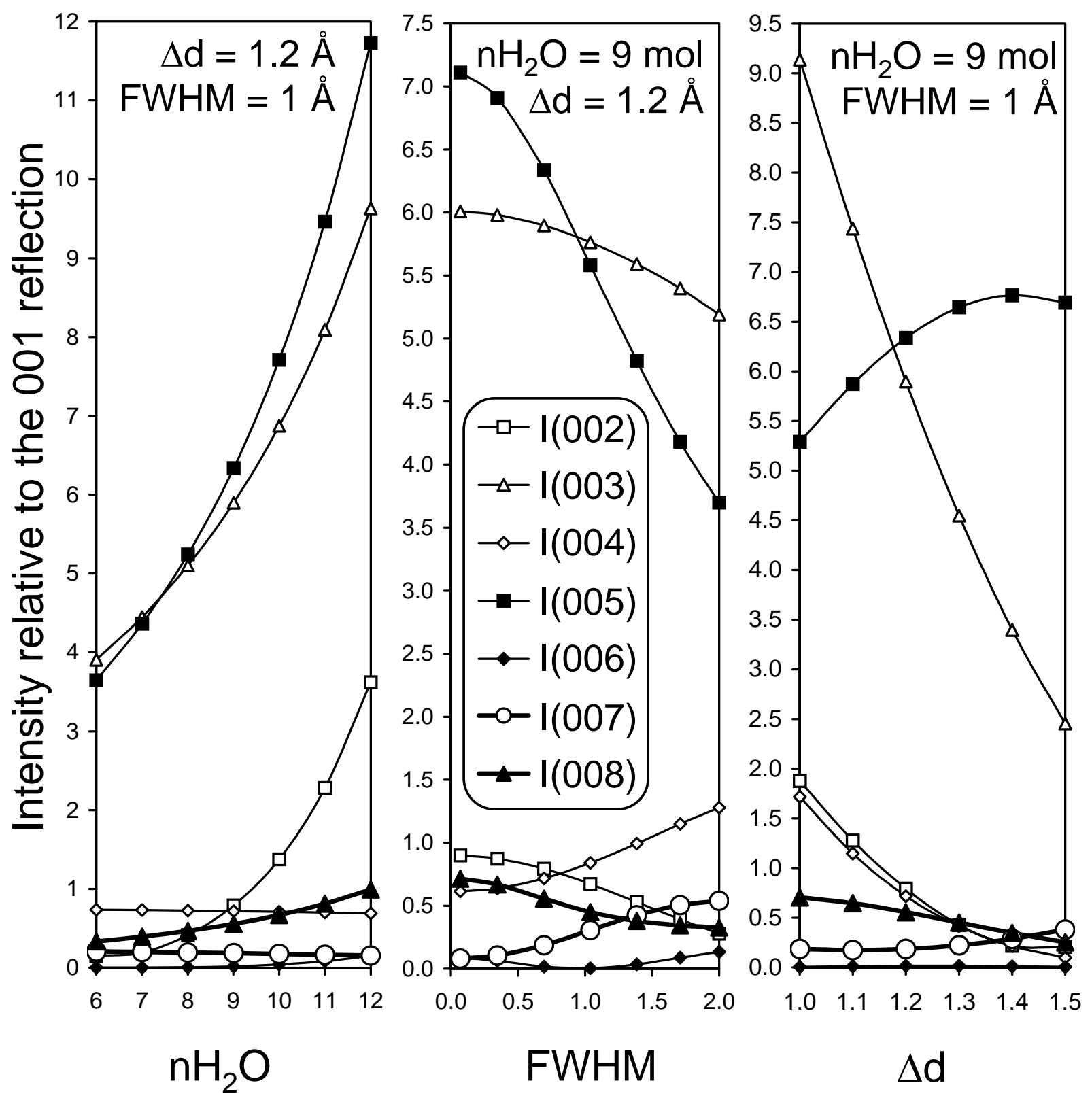

Ferrage et al. Fig. 02 


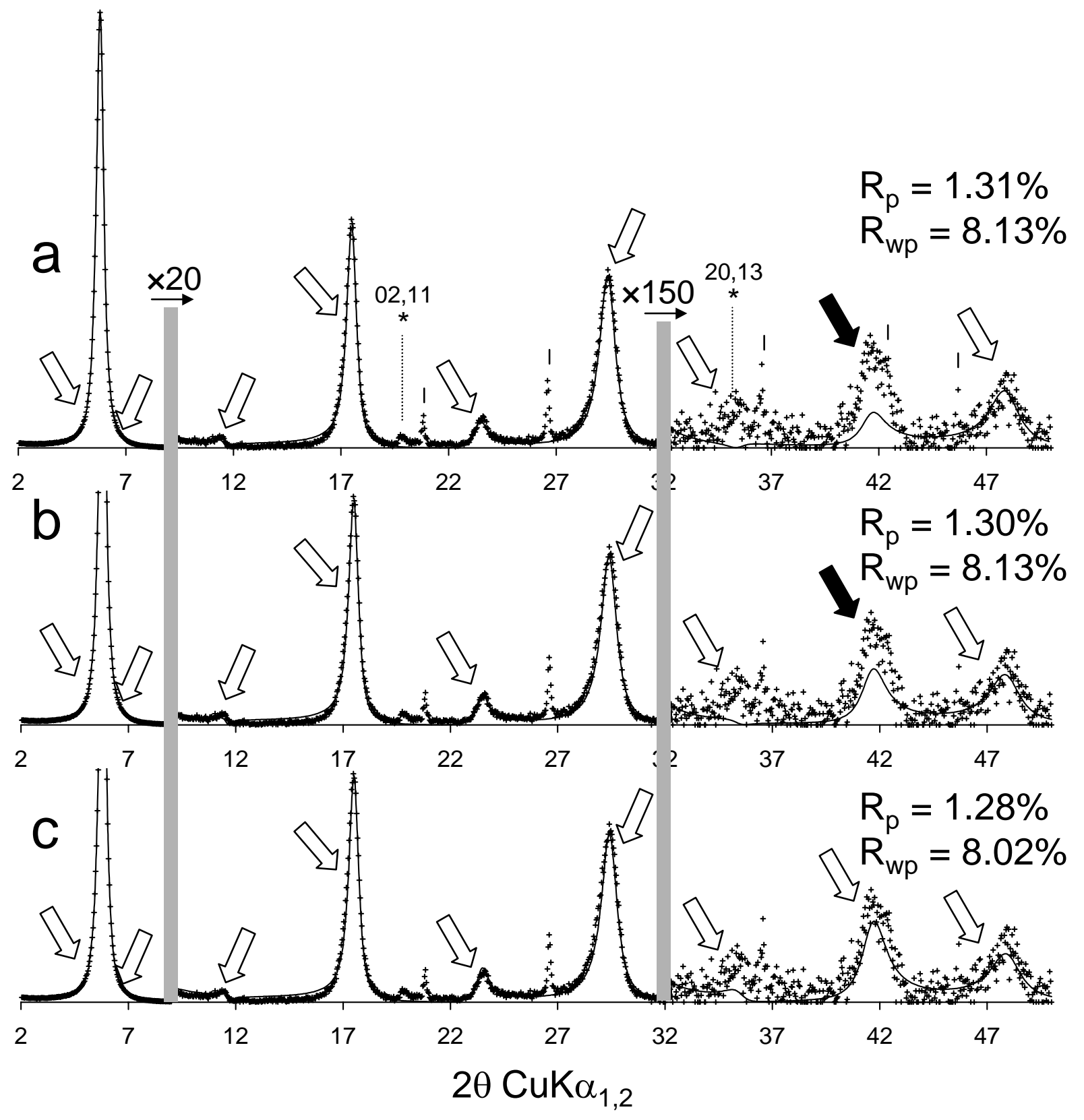

Ferrage et al. Fig. 03 


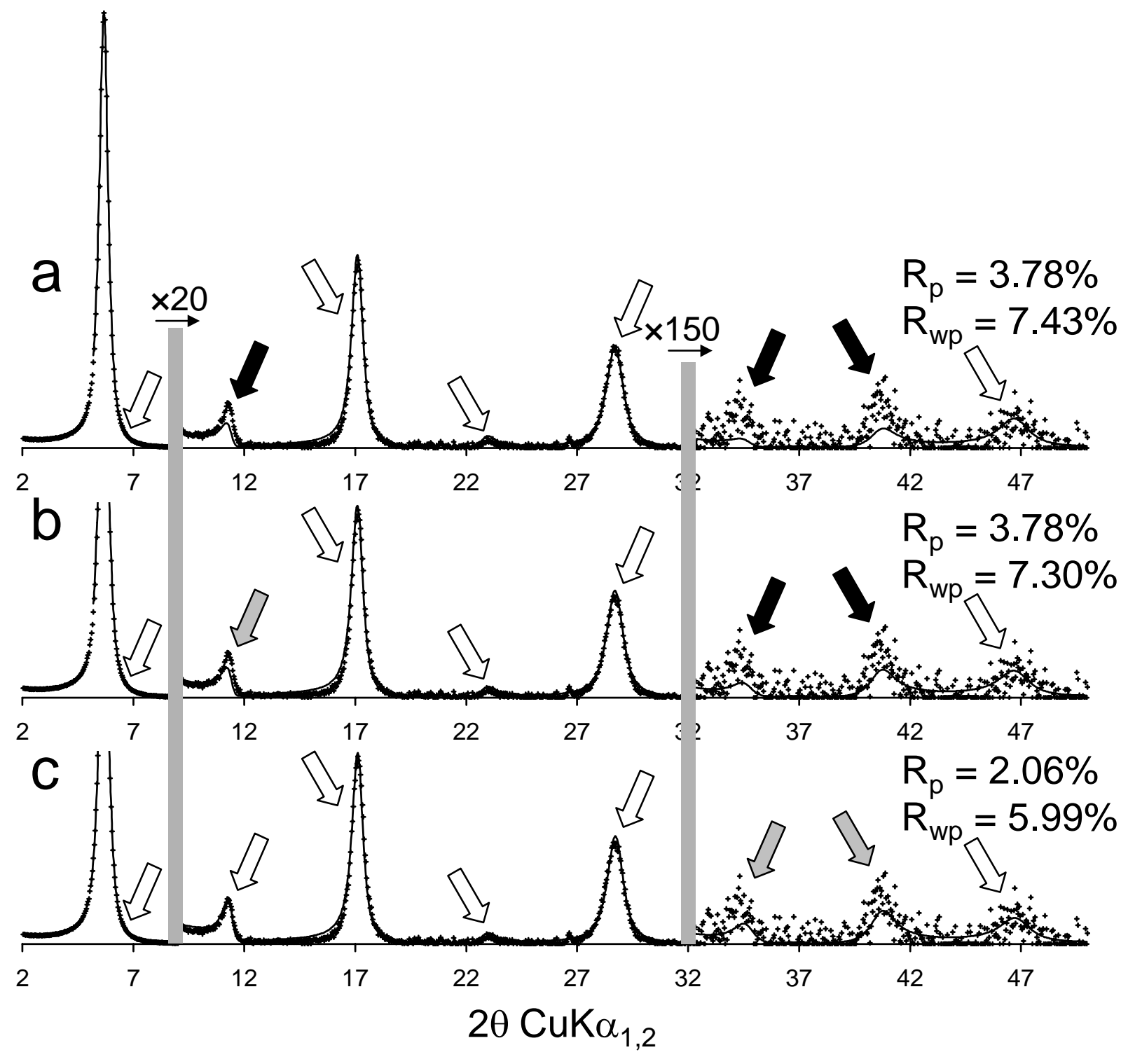

Ferrage et al. Fig. 04 


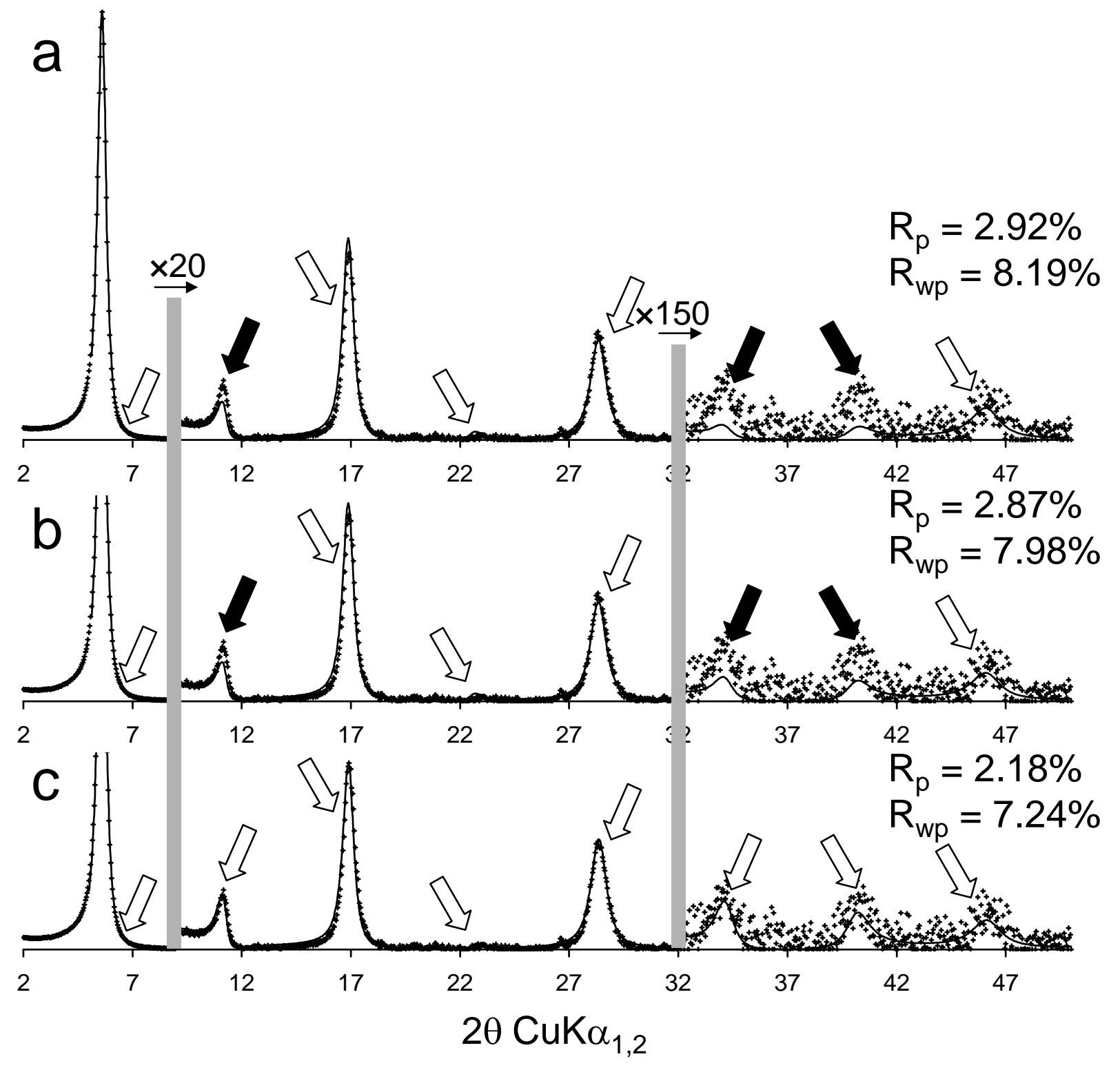

Ferrage et al. Fig. 05 


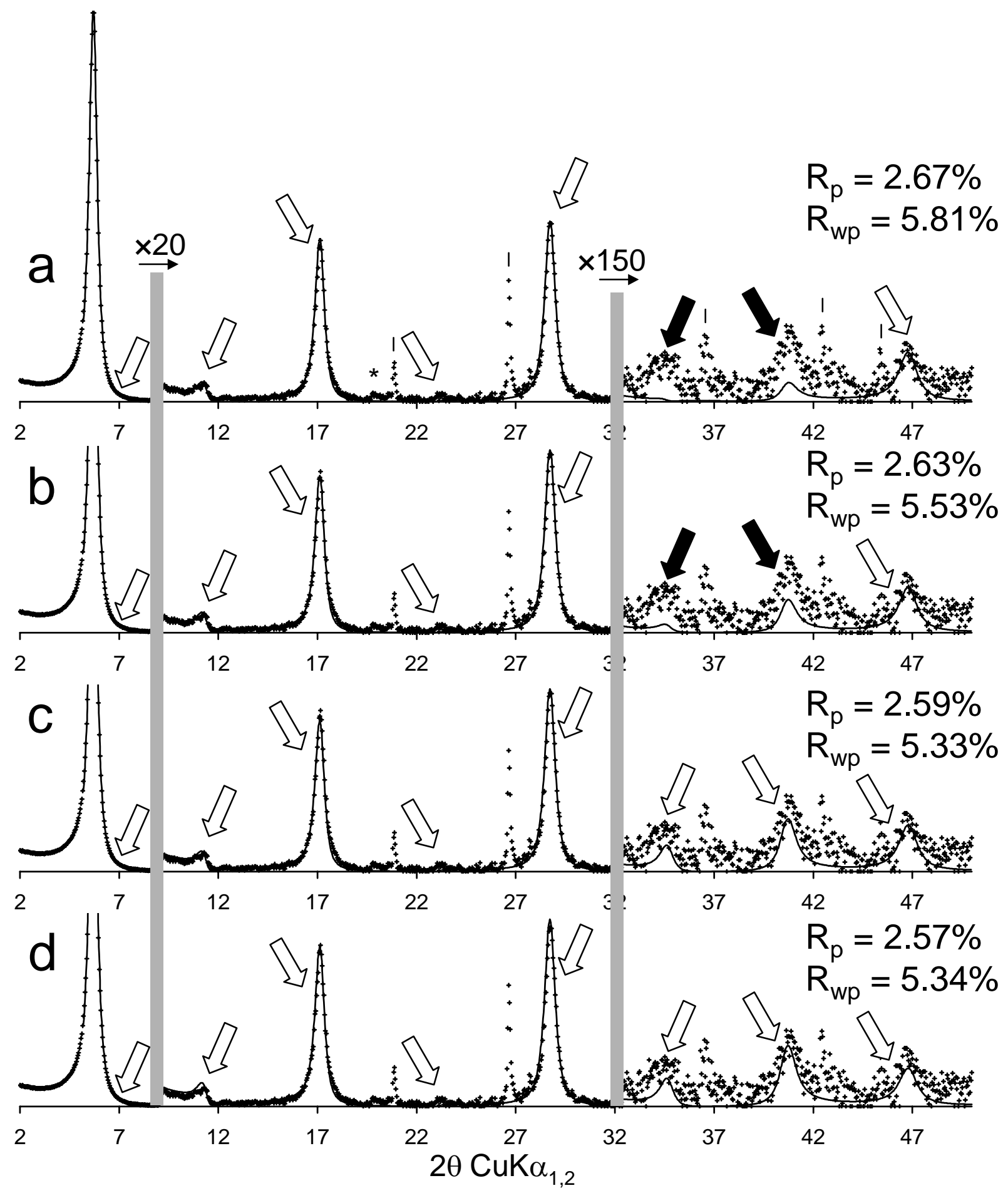

Ferrage et al. Fig. 06 


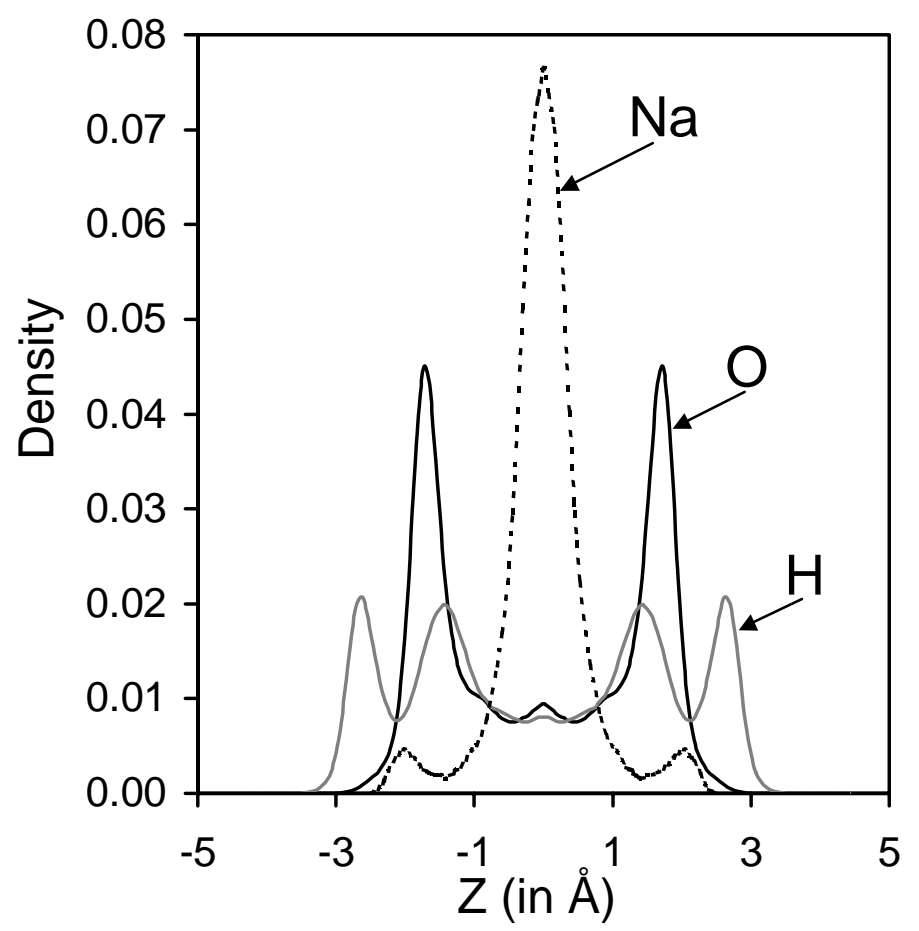

Ferrage et al. Fig. 07 


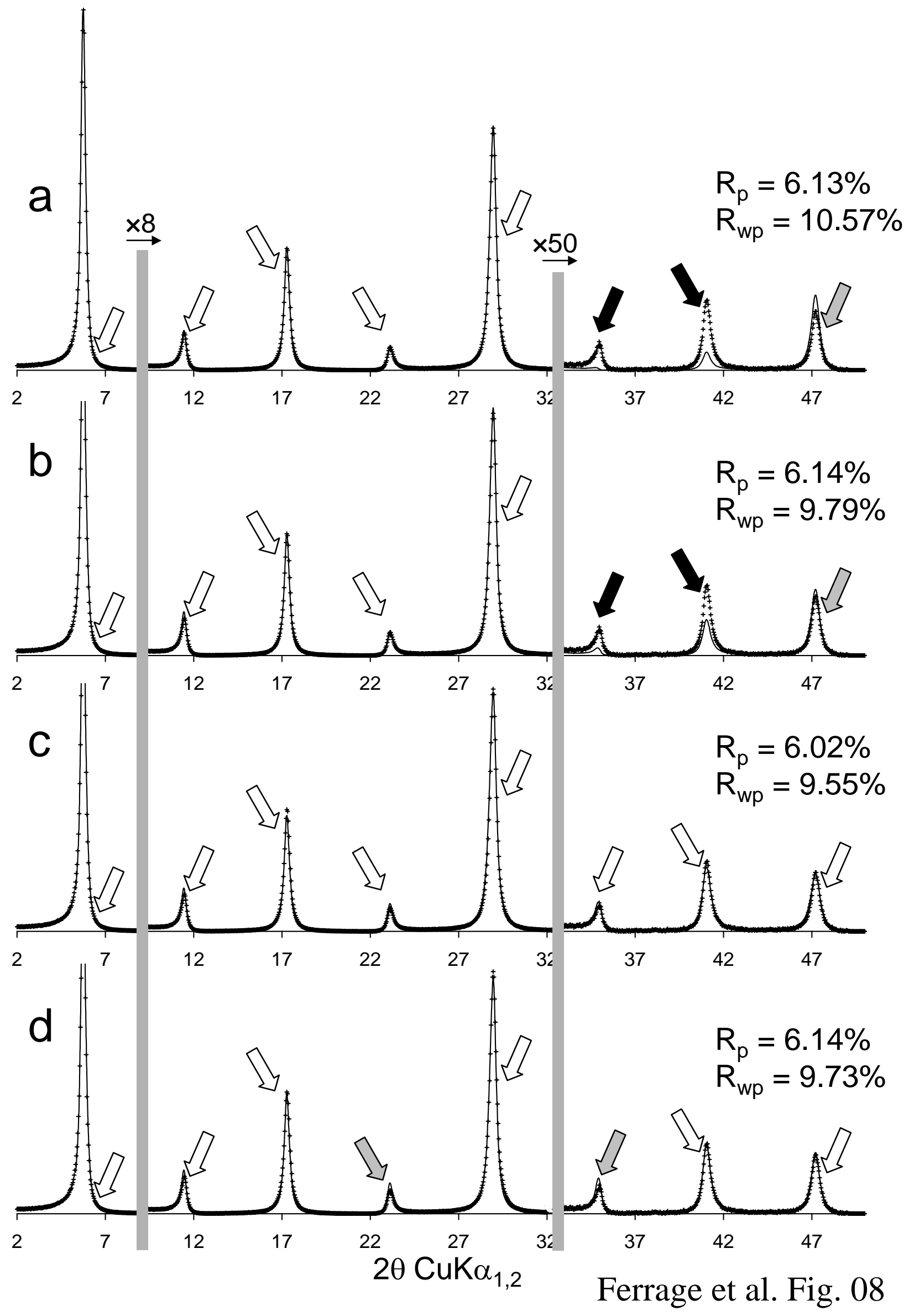



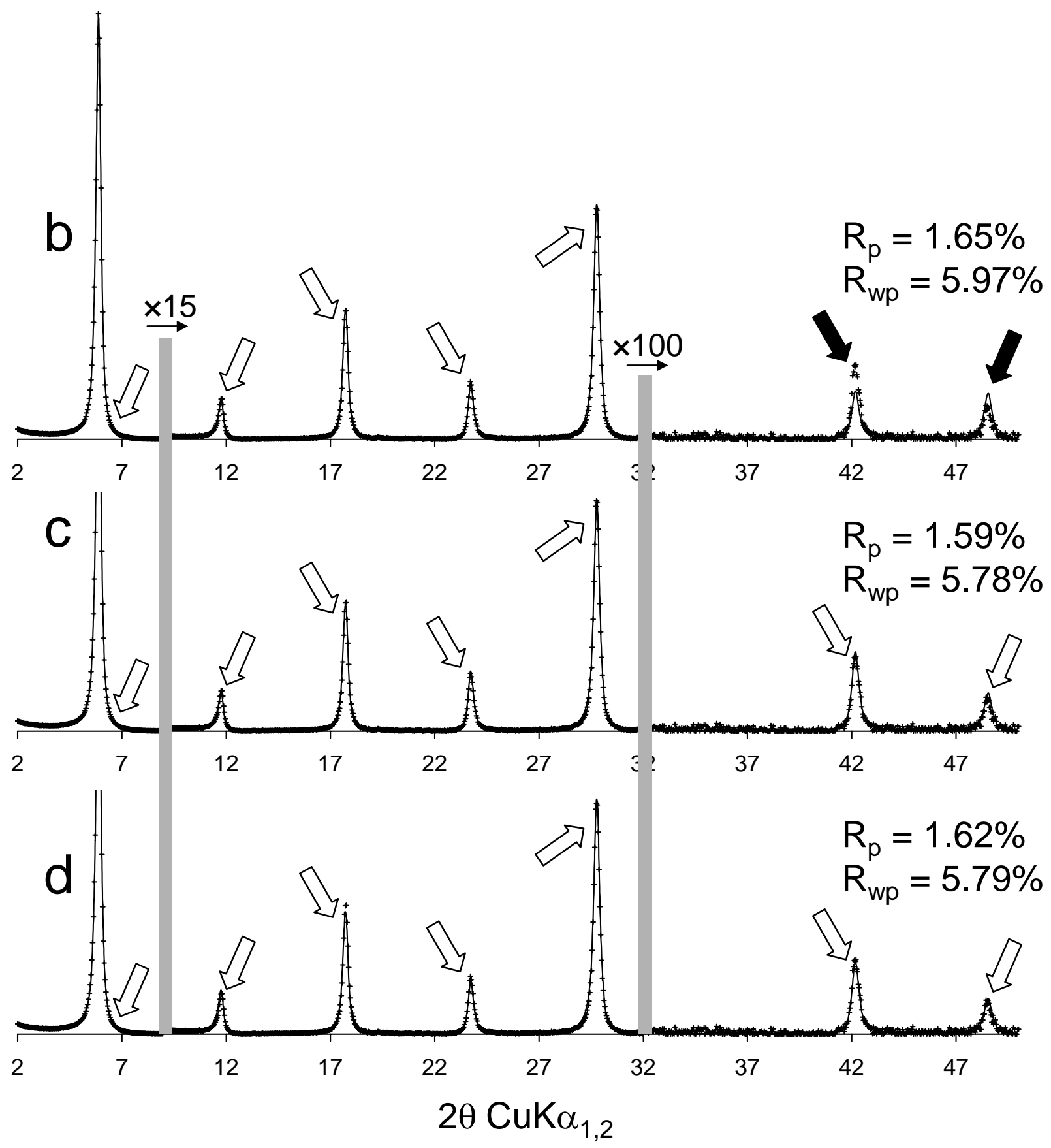

Ferrage et al. Fig. 09 


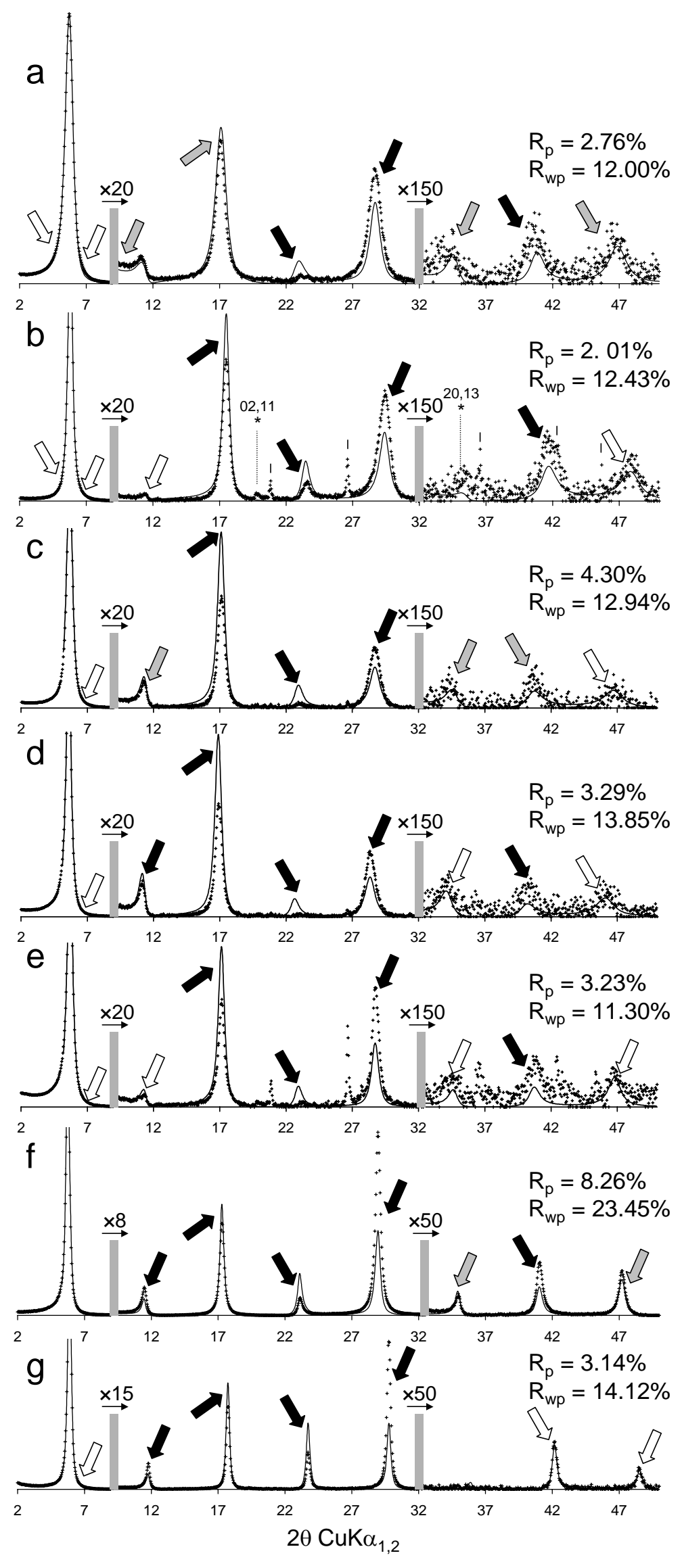

Ferrage et al. Fig. 10 

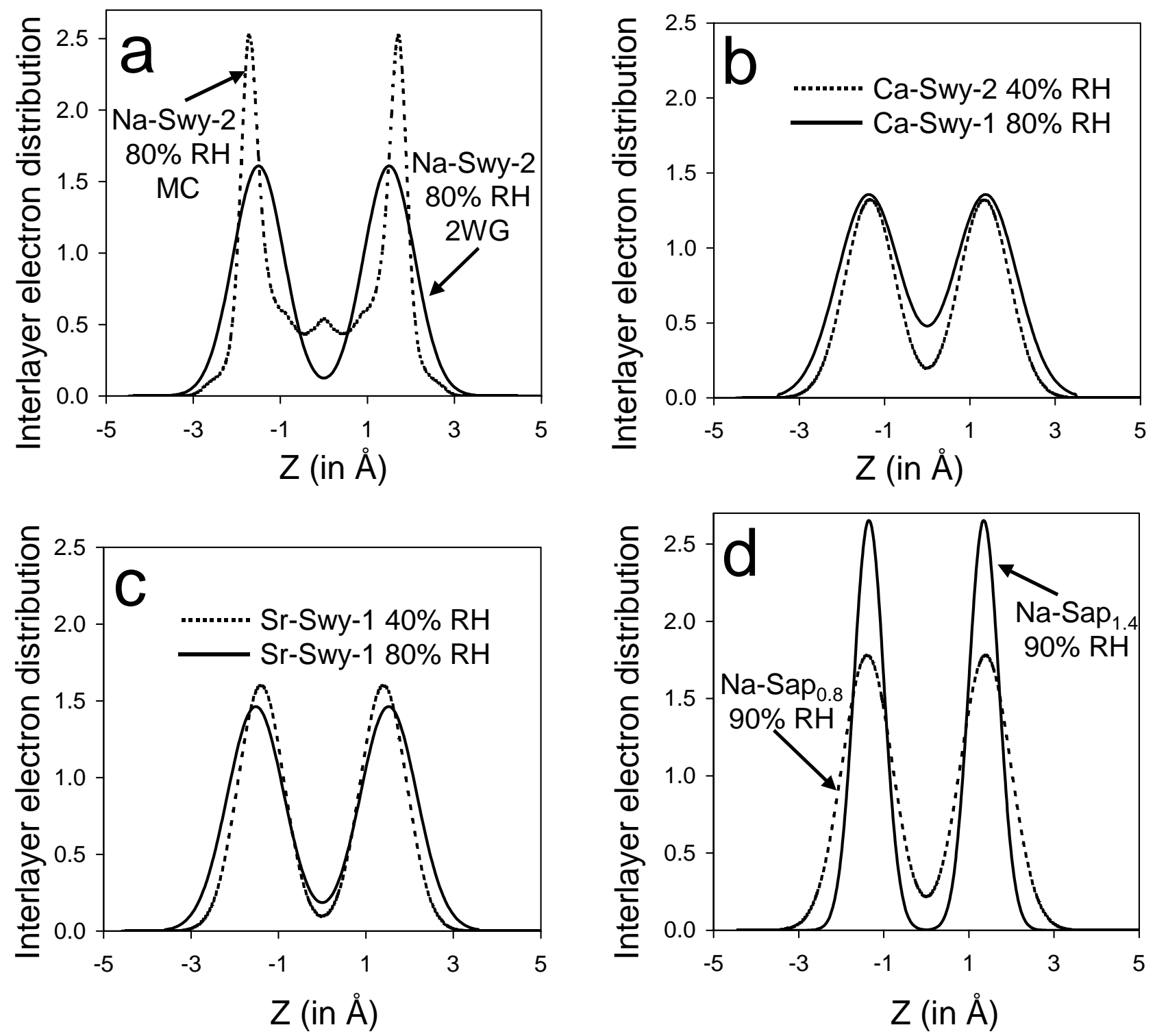

Ferrage et al. Fig. 11 

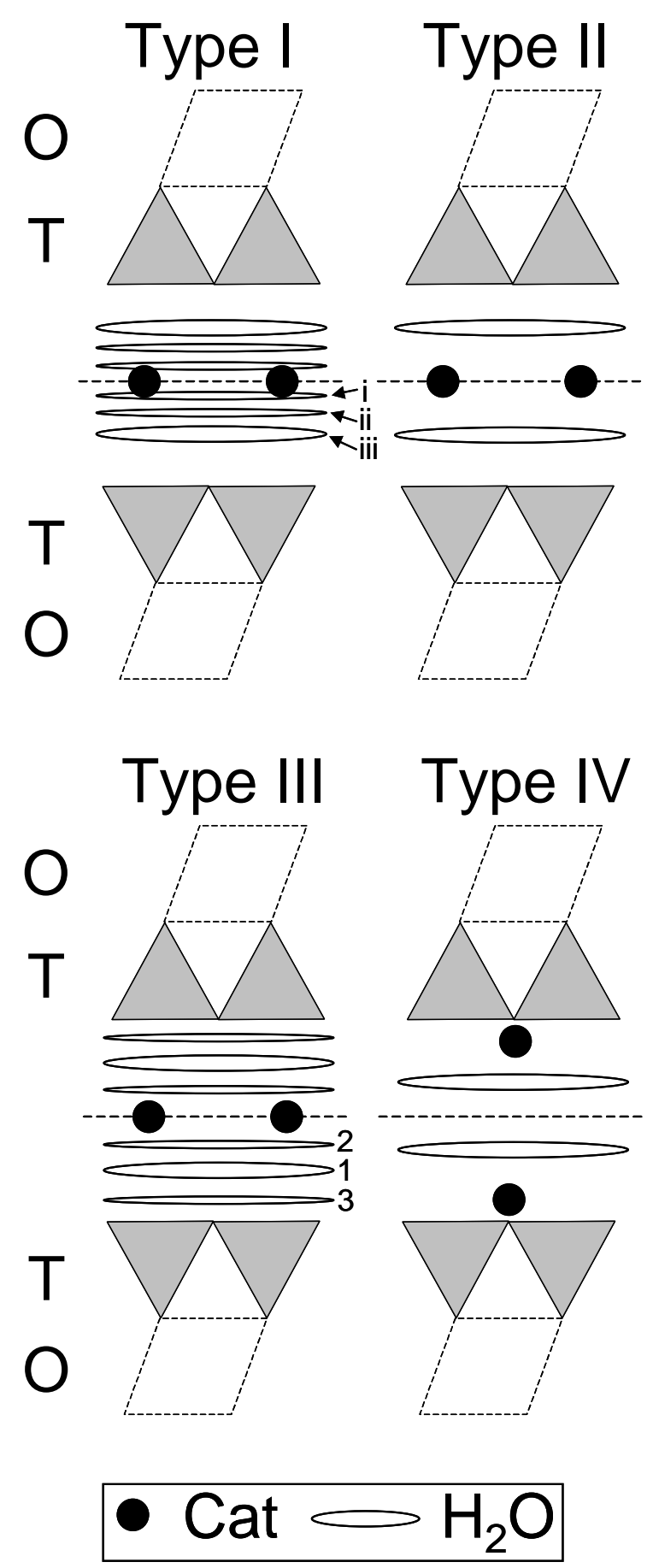

Ferrage et al. Fig. 12 


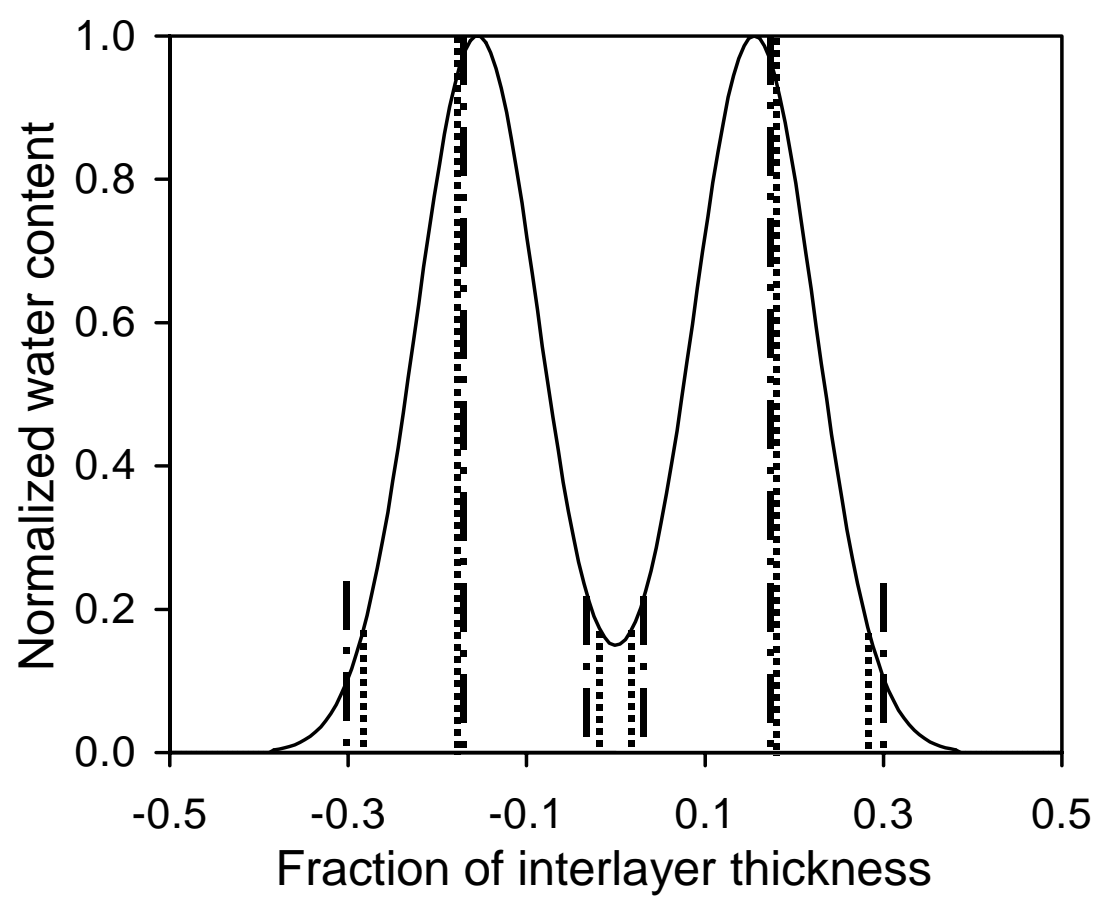

Ferrage et al. Fig. 13 


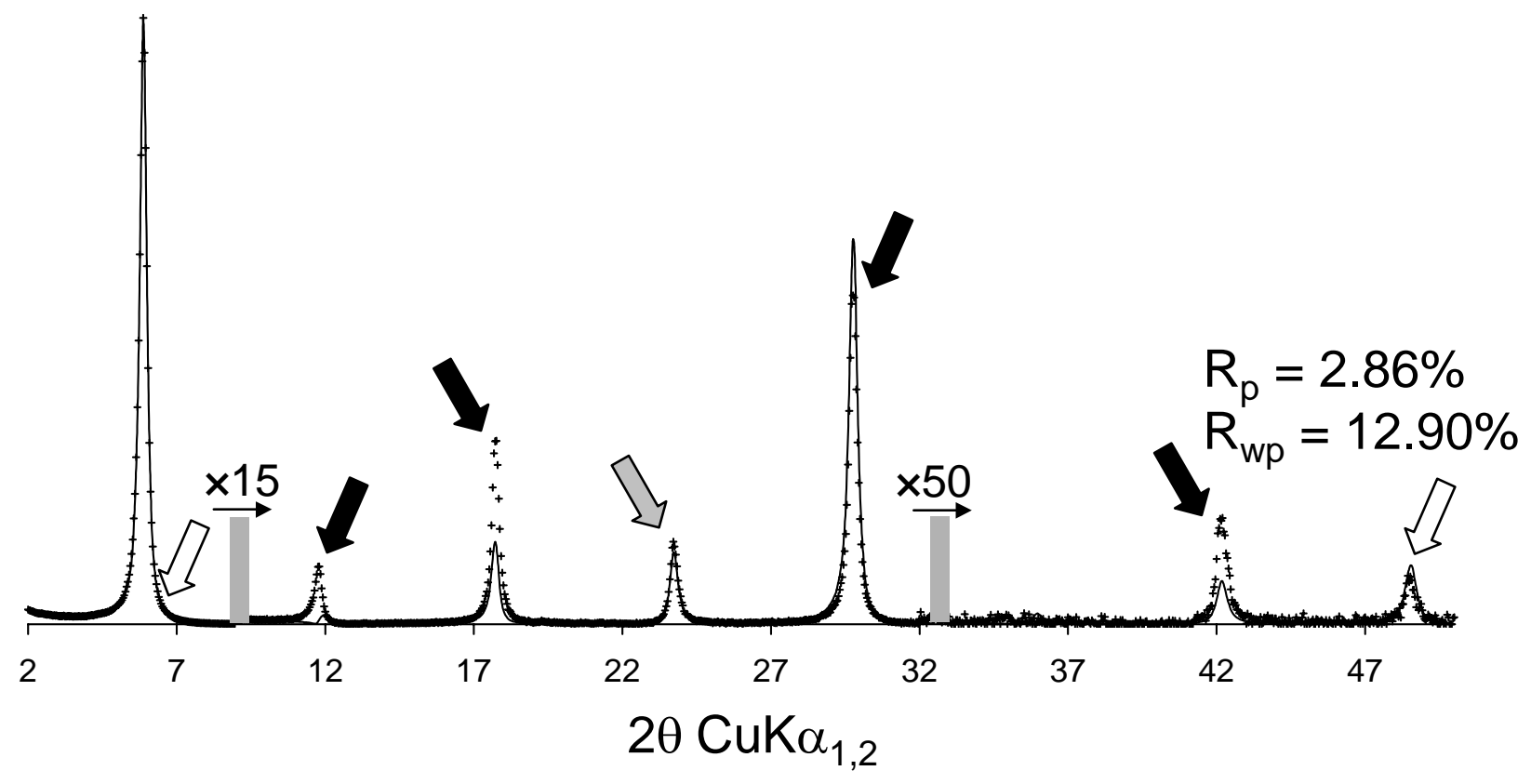

Ferrage et al. Fig. 14 